\title{
ANÁLISE QUANTITATIVA E QUALITATIVA DO CRESCIMENTO DE CAIXETA - Tabebuia cassinoides (LAM.) DC. - EM FLORESTAS MANEJADAS, NO MUNICÍPIO DE IGUAPE/SP
}

\author{
RICARDO BERNHARDT
}

Dissertação apresentada à Escola Superior de Agricultura "Luiz de Queiroz", Universidade de São Paulo, para obtenção do título de Mestre em Recursos Florestais, com opção em Silvicultura e Manejo Florestal.

P I R A C I C A B A

Estado de São Paulo - Brasil

Agosto - 2003 


\title{
ANÁLISE QUANTITATIVA E QUALITATIVA DO CRESCIMENTO DE CAIXETA - Tabebuia cassinoides (LAM.) DC. - EM FLORESTAS MANEJADAS, NO MUNICÍPIO DE IGUAPE/SP
}

\section{RICARDO BERNHARDT}

Engenheiro Florestal

\author{
Orientador: Prof. Dr. VIRGILIO MAURÍCIO VIANA
}

\begin{abstract}
Dissertação apresentada à Escola Superior de Agricultura "Luiz de Queiroz", Universidade de São Paulo, para obtenção do título de Mestre em Recursos Florestais, com opção em Silvicultura e Manejo Florestal.
\end{abstract}

P I R A C I C A B A

Estado de São Paulo - Brasil

Agosto - 2003 


\section{Dados Internacionais de Catalogação na Publicação (CIP) DIVISÃO DE BIBLIOTECA E DOCUMENTAÇ̃̃O - ESALQ/USP}

\section{Bemhardt, Ric ardo}

Aná lise quantitativa e qua litativa do crescimento de caixeta Tabebuia cassinoides (Lam.) DC. - em florestasmanejadas, no município de Iguape/SP. - - Piracic aba, 2003.

61 p. : il.

Dissertação (mestrado) - - Escola Superior de Agricultura Luiz de Queiroz, 2003.

Bibliografia.

1. Ánoresfloresta is 2. Caixeta 3. Ciclo de corte 4. Dendometria 5. Desbrota 6. Manejo florestall. Título

CDD 634.97354 


\section{AGRADECIMENTOS}

Ao Prof. Dr. Virgilio Mauricio Viana pelos ensinamentos e orientação ao longo da minha estada no LASTROP.

À FAPESP pela bolsa de mestrado e reserva técnica.

Ao WWF e Fundação FORD pelo apoio à elaboração deste projeto, via Programa Natureza e Sociedade.

Aos Professores Adriana Maria Nolasco e João Luis Ferreira Batista, pelo apoio ao longo da pesquisa.

À toda a equipe do LASTROP, especialmente Isandra, Mariana, Rui Aparecido Paulo, Leandro, Marcelo Marquesini e Ventania.

Ao IBAMA de Iguape, pelo apoio logístico.

Aos caixeteiros e seu movimento, que foram a motivação deste trabalho. Especialmente Rui, Jordalino, Adélio, Jonas, Dauro, Lino que me ensinaram muito, contribuíram diretamente com a pesquisa e por alegrar o trabalho no caixetal.

À Mariana pelas discussões, sugestões e contribuições ao longo da pesquisa. 
Aos meus pais Lutz e Regina, pela oportunidade de estudar e por todo apoio que sempre me deram.

À minha companheira Cristiana por todo o apoio, compreensão e paciência ao longo deste trabalho. 


\section{SUMÁRIO}

Página

LISTA DE FIGURAS .......................................................................... vii

LISTA DE TABELAS …................................................................... viii

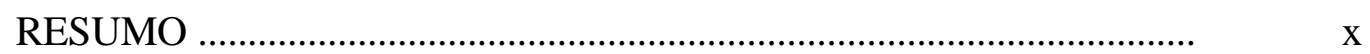

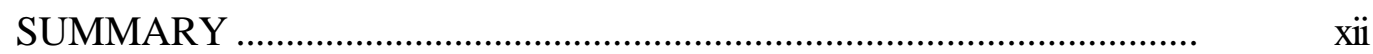

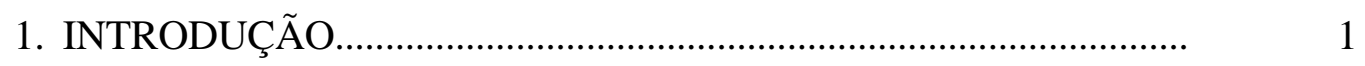

2. REVISÃO DE LITERATURA .........................................................

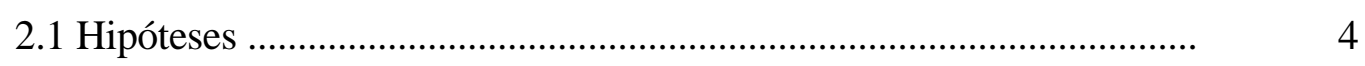

2.2 Justificativas ................................................................................

2.3 Predições ............................................................................... 5

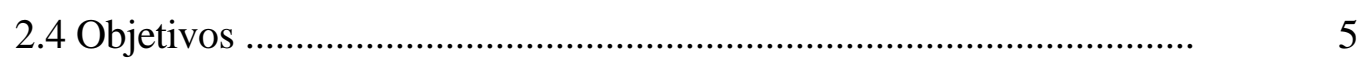

3 Crescimento e qualidade de fuste de brotações de caixeta Tabebuia cassinoides (LAM.) DC. - 8 anos após a colheita 6

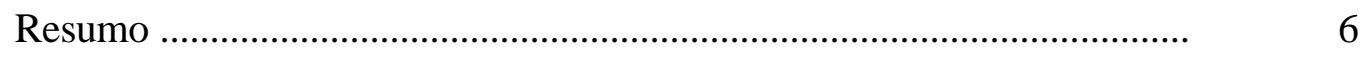

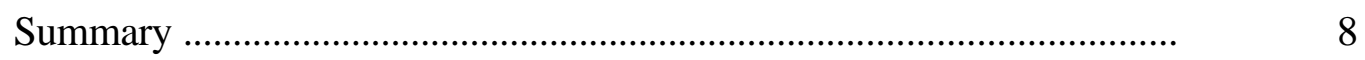

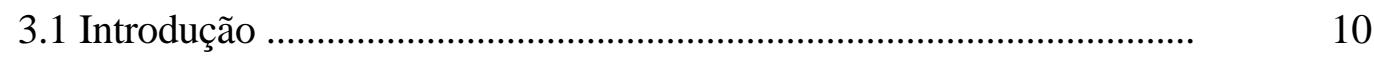

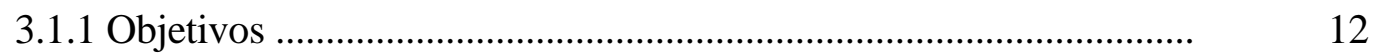

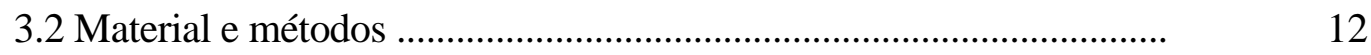

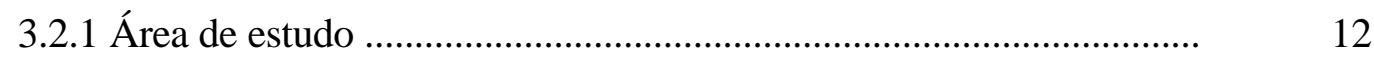

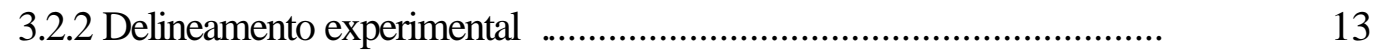

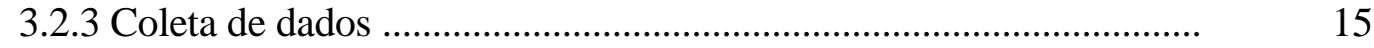

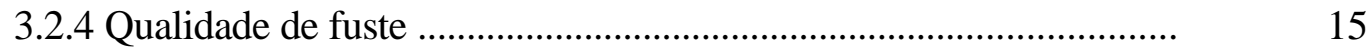

3.3 Resultados e discussão ...................................................................... 16

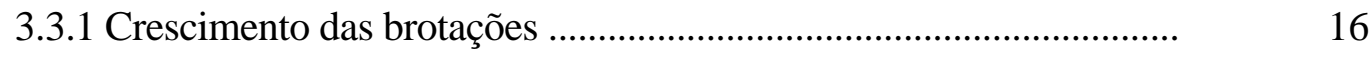

3.3.2 Qualidade de fuste ....................................................................... 25 
3.4 Conclusões

4 Incremento volumétrico de dois caixetais manejados no município de Iguape/SP 30

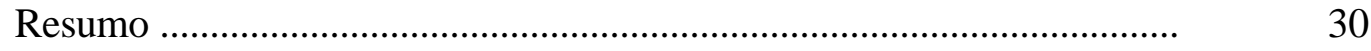

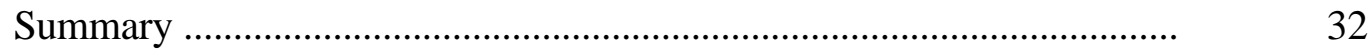

4.1 Introdução ........................................................................................ 33

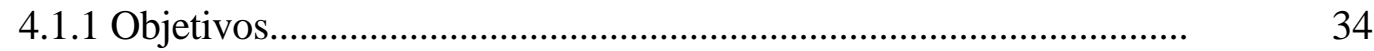

4.2 Materiais e Métodos ...................................................................... 34

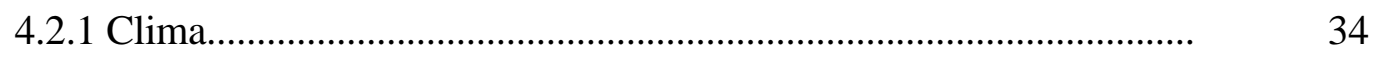

4.2.2 Área de estudo......................................................................... 35

4.2.3 Inventário florestal..................................................................... 36

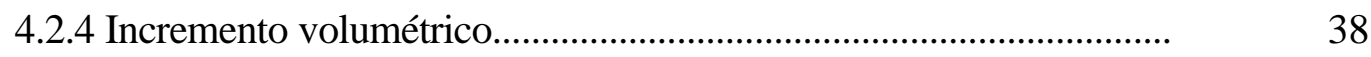

4.2.5 Determinação do ciclo de colheita ...................................................... 40

4.3 Resultados e Discussão ...................................................................... 41

4.3.1 Incremento médio anual.......................................................................

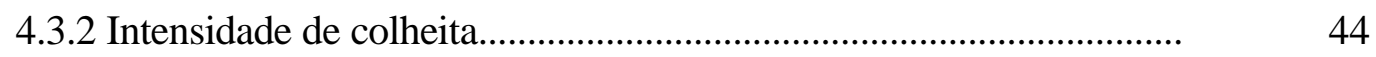

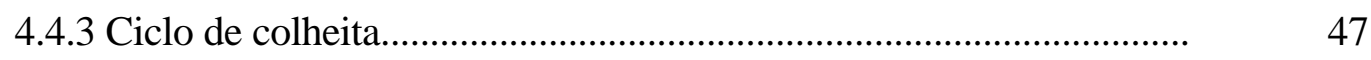

4.4 Conclusões .............................................................................. 48

5 CONCLUSAO GERAL $\quad 50$

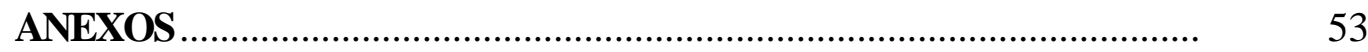

REFERÊNCIAS BIBLIOGRÁFICAS............................................... 57 


\section{LISTA DE FIGURAS}

Página

1 Croqui da área de pesquisa com a disposição dos blocos do experimento de desbrota (SILVA, 2000)

2 Diâmetro médio de fuste por tratamento por ano de coleta de dados....

3 Altura média de fustes por tratamento por ano de coleta de dados

4 Incremento Médio Anual em diâmetro (cm/fuste/ano), por tratamento de desbrota

5 Incremento Médio Anual em altura (m/fuste/ano), por tratamento de desbrota.

6 Croqui do caixetal da área experimental da Fazenda Retiro, indicando as parcelas de inventário florestal (Silva, 2000)

7 Croqui do caixetal da área experimental da Fazenda Cindumel, indicando as parcelas de inventário florestal (Silva, 2000) 


\section{LISTA DE TABELAS}

Página

1 Fatores, níveis e respectivos tratamentos para os experimentos com brotação (Silva, 2000)

2 Época de instalação e coleta dos dados do experimento de brotação ...

3 Resultado da ANAVA, para a variável DAP, aos 8 anos após a colheita

4 Valores médios de DAP $(\mathrm{cm})$ por tratamento, por ano de coleta de dados

5 Valores médios de altura dos brotos $(\mathrm{m})$ por tratamento, por ano de coleta de dados

6 Incremento Médio Anual em diâmetro (cm/fuste/ano), por tratamento

7 Incremento Médio Anual em altura por tratamento

8 Valor médio, máximo e mínimo de altura da primeira bifurcação para brotações de caixeta 8 anos após a colheita, Iguape/SP

9 Proporção de fustes por classe de tortuosidade

10 Resultado do teste de Tukey para comparação da influência da desbrota sobre a qualidade de fuste

11 Época das medições do Inventário Florestal nas áreas experimentais

12 Incremento médio anual em volume, considerando indivíduos com CAP $>35 \mathrm{~cm}$, Fazenda Retiro, Iguape/SP.

13 Incremento médio anual em volume, considerando indivíduos com CAP $>35 \mathrm{~cm}$, Fazenda Cindumel, Iguape $/ \mathrm{SP}$.

14 Volume de madeira existente e remanescente $\left(\mathrm{m}^{3} / \mathrm{ha}\right)$ e intensidade de colheita para as áreas experimentais, Iguape/SP. 
15 Intensidades de colheita, mínima e máxima observadas para as áreas

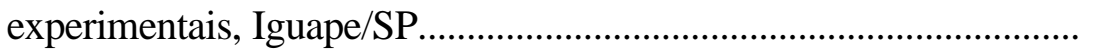

16 Incremento Médio Anual $\left(\mathrm{m}^{3} / \mathrm{ha} / \mathrm{ano}\right)$ por classe de intensidade de colheita para as áreas experimentais, Iguape/SP.

17 Volume de madeira colhido, IMA e ciclo de colheita para as áreas experimentais, Iguape/SP. 


\title{
ANÁLISE QUANTITATIVA E QUALITATIVA DO CRESCIMENTO DE CAIXETA - Tabebuia cassinoides (LAM.) DC. - EM FLORESTAS MANEJADAS, NO MUNICÍPIO DE IGUAPE/SP
}

\author{
Autor: RICARDO BERNHARDT \\ Orientador: Prof. Dr. VIRGILIO MAURÍCIO VIANA
}

\section{RESUMO}

A caixeta - Tabebuia cassinoides (LAM.) DC. - é uma espécie que ocorre nas planícies de inundação da Floresta Atlântica. Seu uso comercial iniciou na década de 30, principalmente para a produção de tamancos e lápis. A exploração da caixeta foi proibida em 1989, pela Portaria IBAMA ñ 218. Em função da sua importância para as comunidades e da pressão exercida pelas mesmas, o manejo foi regulamentado em 1992, pela Resolução SMA 11, da Secretaria do Meio Ambiente do Estado de São Paulo. A Resolução regulamenta o manejo da caixeta sob regime de rendimento auto sustentado. $\mathrm{O}$ ciclo de corte foi estabelecido em 12 anos, porém não se baseou em informações técnico-científicas. As informações sobre o crescimento e produtividade de florestas tropicais são escassas e essenciais para verificar a sustentabilidade técnica, ambiental e econômica do manejo florestal. Dessa forma, a checagem do ciclo proposto é fundamental para garantir a sustentabilidade do manejo da caixeta. 
Como a caixeta emite vigorosa brotação após a colheita, uma das principais práticas silviculturais pós-colheita é a desbrota. A Resolução SMA 11/92, estabelece que devem ser deixados de 1 a 3 brotos por cepa.. Com o objetivo de verificar o crescimento e qualidade de fuste em função da quantidade de brotos foi estabelecido um experimento com 224 cepas.

A partir do acompanhamento do Inventário Florestal da Fazenda Retiro (50 parcelas 10 x 20m) e Fazenda Cindumel (46 parcelas 10 x 20m), observou-se Incremento Médio Anual (IMA) de 3,215 $\pm 0,366 \mathrm{~m}^{3} / \mathrm{ha} /$ ano e 5,557 $\pm 0,598 \mathrm{~m}^{3} / \mathrm{ha} / \mathrm{ano}$, respectivamente. Analisando a intensidade de colheita das áreas observourse que a mesma foi superior a $50 \%$ do volume de madeira passível de colheita e que nas áreas próximas às rotas de extração a intensidade foi maior, chegando a 94\%. Kto acarretou numa redução de até $54 \%$ do IMA, para as áreas em que a intensidade de colheita foi superior a 75\%. Com as estimativas do IMA foi estimado o Intervalo de Confiança para o ciclo de colheita, que variou de 12,9 a 17,6 anos.

O acompanhamento do experimento de desbrota, 8 anos após a colheita, indica que os tratamentos em que foram deixados 1 e 2 brotos não diferem estatisticamente entre si e apresentam diâmetro médio das brotações de 8,95 cm e 8,37 $\mathrm{cm}$, respectivamente. Enquanto os tratamentos em que foram deixados 3 e todas os brotos apresentam diâmetro médio de 7,30 cm e 5,37 cm, respectivamente. A aplicação da desbrota melhorou significativamente a qualidade de fuste, aumentando a altura da $\mathrm{F}$ bifurcação e reduzindo a tortuosidade em todos os tratamentos, quando comparada ao tratamento testemunha.

Os resultados de pesquisa apontam para a necessidade de revisão da Resolução SMA 11/92, para garantir a sustentabilidade do manejo da caixeta, nos seguintes aspectos: (i) estabelecimento de um limite pra a intensidade de colheita, de até $75 \%$ nas áreas próximas às rotas de extração; (ii) o número de brotos a ser deixado por cepa deve ser de 1 a 2, e; (iii) o ciclo colheita de 12 anos é subestimado.

Palavras chave: caixeta, Tabebuia cassinoides (LAM.) DC., manejo florestal, ciclo de corte, desbrota, incremento volumétrico 


\title{
QUANTITATIVE AND QUALITATIVE ANALYSIS OF THE GROWTH CAIXETA - Tabebuia cassinoides (LAM.) DC. - IN FOREST HANDELED IN THE MUNICIPAL DISTRICT OF IGUAPE/SP
}

\author{
Author: RICARDO BERNHARDT
}

Adviser: PROF. DR. VIRGILIO MAURICIO VIANA

\section{SUMMARY}

Caixeta - Tabebuia cassinoides (LAM.) DC. - is a tree species of swamp forests in the Atlantic Rain Forest. It has been used since the 30's, mainly for clog and pencil production. IBAMA Decree no. 218 prohibited Caixeta's explotation in 1989. By its importance for the community and social movement, caixeta's management was regulated by the Resolution 11/92 by the Environmental Secretary of São Paulo State. This Resolution regulates caixeta management by auto-sustained regime. The cutting cycle was defined as 12 years, but isn't based on technical and scientific data. Information about growth and yield are rare for Tropical Rain Forest. This information is essential to verify technical, environmental and economic sustainability of the forest management. Thus, check the proposed cutting cycle is fundamental to certify the sustainability of caixeta management. After harvest caixeta sprouts vigorously, so one the most important silvicultural practice is sprout thinning. Resolution ES 11/92, establishes that must be left 1 to 3 sprouts per stump. Objectifying to verify growth and stem quality of the sprouts was established an experimental area composed by 224 stumps. By the Forest Inventory measurement of Retiro Farm (50 samples 10 x 20 m) and Cindumel Farm (46 samples 10 x 20 m), was observed Mean Annual Increment for 
volume of $3,215 \pm 0,366 \mathrm{~m}^{3} / \mathrm{ha} /$ year and $5,557 \pm 0,598 \mathrm{~m}^{3} /$ ha/year, respectively. The harvest intensity was over $50 \%$ of the amount harvestable wood; the intensity was higher near the extraction routes, reaching 94\%. Thus caused a reduction of 54\% in MAI, where the harvest intensity was higher than $75 \%$. The estimated harvest cycle for managed caixetais has Confident Interval from 12,9 to 17,6 years. The measurement of thinning sprout experiment, 8 years after logging, indicates that treatments that have 1 and 2 sprouts are statistically equal, and have mean $\mathrm{DBH}$ of $8,95 \mathrm{~cm}$ and $8,37 \mathrm{~cm}$, respectively. While the treatments that have 3 and all sprouts have mean DBH of 7,30 $\mathrm{cm}$ and 5,37 cm, respectively, for the same period. Sprout thinning improves stem quality, increasing the height of first fork and reducing stem sinuosity, when compared with sprouts without thinning.

The research results pointed to the need of Resolution 11 review, searching for the sustainability of caixeta management. The points that must be reviewed, are: (i) establishment of a limit of harvest intensity lesser than $75 \%$, nearby the extraction routes; (ii) the number of the sprouts per sump must be 1 or 2, and; (iii) the harvest cycle of 12 years is underestimated.

Key-words: caixeta, Tabebuia cassinoides (LAM.) DC., forest management, cutting cycle, sprout thinning, volumetric increment 


\section{INTRODUÇÃO}

As formações florestais brasileiras têm ampla extensão e alta diversidade de espécies, o que representa um grande potencial para uso sustentável atual e futuro. O território brasileiro congrega mais de $10 \%$ de toda a biodiversidade do planeta, sendo a Floresta Tropical Atlântica, genericamente chamada de Mata Atlântica, um dos ecossistemas mais ricos em biodiversidade do mundo (Mittermeier, 1992). A Mata Atlântica estendia-se da região Nordeste do país até o Rio Grande do Sul, por 17 estados, cobrindo cerca de $15 \%$ da superfície do país, onde hoje vivem em torno de 100 milhões de pessoas (Fundação SOS Mata Atlântica \& INPE, 2001).

Atualmente, o Estado de São Paulo possui apenas 7,64 \% de sua área originalmente coberta por florestas nativas, o que correspondia em 1500 a 81,8\%, sendo a região do Vale do Ribeira a que concentra os maiores remanescentes florestais, área exclusiva de Mata Atlântica (Fundação SOS Mata Atlântica \& INPE, 1998).

Nas planícies de inundação sob domínio Atlântico ocorre a caixeta, Tabebuia cassinoides (Lam.) DC. - Bignoniaceae, uma espécie arbórea de pequeno a médio porte, que atinge em torno de 15 metros de altura e $70 \mathrm{~cm}$ de diâmetro, com copa normalmente pequena e de formato arredondado (Carvalho, 1994; Lorenzi, 1992). Nos locais onde a caixeta apresenta dominância superior a 50\%, as florestas são comumente denominadas "caixetais" (Silva, 2000).

A utilização comercial da caixeta é feita desde a década de 30 , tendo sido utilizada principalmente na fabricação de lápis e tamancos. A utilização da madeira de caixeta para esses produtos se deve às suas características físico-mecânicas, como baixa densidade, grã-direita, textura fina, mole, superfície lisa e boa trabalhabilidade. A atividade produtiva relacionada à caixeta foi muito importante para a economia do Vale 
do Ribeira e só no município de Iguape chegou a envolver 250 famílias, direta ou indiretamente (Diegues, 1991).

O declínio da atividade relacionada à extração de caixeta se iniciou na década de 80, com a entrada no mercado de madeira oriunda de plantações (Pinus sp.) e em função da intensa exploração dos caixetais da região (Diegues, 1991). A intensa exploração dos caixetais foi resultado do baixo grau de planejamento, manejo inadequado da espécie e da baixa eficiência no aproveitamento dos recursos florestais (Nolasco, 2000).

A paralisação legal de seu corte ocorreu em 1989, pela Portaria $n^{0} 218$ do IBAMA, que impedia qualquer tipo de exploração em área de Mata Atlântica, até sua regulamentação. Esta situação levou a população envolvida na atividade de extrativismo e beneficiamento de caixeta, a se organizar através da "Associação do Caixeteiros" (Associação de Reposição e Recuperação Florestal da Mata Atlântica - Iguape Refloresta) e exigir uma solução das autoridades responsáveis. A solução veio com a regulamentação do manejo de caixetais no Estado de São Paulo, através da Resolução SMA 11/92 (Secretaria do Meio Ambiente do Estado de São Paulo) e apoiada pelo Decreto Federal 750/93, que dispõe sobre o corte, a exploração e a supressão de vegetação na Mata Atlântica.

Em 1992 teve início o "Projeto Caixeta" desenvolvido por instituições de ensino (ESALQ/USP e NUPAUB/USP), ONG's (União dos Moradores da Juréia, REBRAF e PROTER) e a "Associação dos Caixeteiros", financiado pela Fundação Ford. O programa de pesquisa tinha como objetivo gerar informações e propor ações para conservar a biodiversidade e melhorar a qualidade de vida das populações locais.

Em 1995, foi iniciado o projeto "Manejo Integrado e Sustentável de Florestas de Caixeta no Vale do Ribeira - SP", desenvolvido pela ESALQ/USP, através do Departamento de Ciências Florestais e financiamento da FAPESP. Tratourse de um projeto temático que teve por objetivo desenvolver tecnologia de manejo e processamento de recursos florestais com sólidas bases biológicas e silviculturais, viabilizando a implantação de um modelo mais sustentável de produção, conciliando a conservação ambiental com a melhoria da qualidade de vida da população local (Nolasco, 2000). A partir desse projeto foi desenvolvida a dissertação de mestrado de 
Silva (2000) intitulada "Subsídios para o manejo de Tabebuia cassinoides (LAM.) DC. (Caixeta) - Ecologia, Silvicultura e Manejo Florestal", que em um dos capítulos abordou a questão da aplicação da desbrota após a colheita e seus efeitos sobre o desenvolvimento das brotações. Após 44 meses da colheita Silva (2000) constatou que a prática silvicultural da desbrota após a colheita é fundamental para o manejo de caixetais. A presente dissertação segue a mesma linha de pesquisa do Projeto Temático. Utiliza as parcelas de Inventário Florestal e os experimentos de desbrota, instalados durante o projeto, para fazer uma análise quantitativa e qualitativa do crescimento da caixeta e caixetais, em função das práticas silviculturais aplicadas. 


\section{REVISÃO DE LITERATURA}

O problema de pesquisa é a falta de informação sobre o crescimento e a influência das práticas silviculturais sobre a caixeta e os caixetais. A falta dessas informações dificulta o planejamento operacional, assim como a análise da viabilidade técnica, ambiental e econômica do manejo florestal (FAO, 1998).

Para a busca da sustentabilidade do manejo florestal em longo prazo, é fundamental conhecer o crescimento da floresta e sua produtividade (Amaro \& Tome, 1999; Vanclay, 1994). Como são poucas as informações sobre incremento volumétrico para florestas tropicais, é comum que o volume de madeira colhida seja superior ao incremento da floresta, fazendo com que a disponibilidade de madeira decresça drasticamente, podendo inviabilizar as atividades relacionadas ao manejo florestal (Rompaey, 2001).

\subsection{Hipóteses}

(i) $\mathrm{O}$ ciclo de corte para a caixeta deve ser superior ao ciclo proposto pela Resolução SMA 11/92, que é de 12 anos;

(ii) A desbrota, prática silvicultural pós-colheita, influi significativamente sobre o desenvolvimento e a qualidade de fuste de caixeta.

\subsection{Justificativas}

(i) A informação sobre o ciclo de colheita é pouco freqüente para florestas nativas, devido ao longo período de acompanhamento e medições, necessário para se produzir tais estimativas; 
(ii) $\mathrm{O}$ conhecimento das taxas de crescimento de florestas tropicais é muito reduzido, apesar de sua vital importância para o planejamento das colheitas dentro de níveis sustentáveis;

(iii) $\mathrm{O}$ desconhecimento do ciclo de corte para caixeta dificulta análises de sustentabilidade ambiental e econômica de seu manejo em longo prazo;

(iv) A análise em longo prazo das práticas silviculturais, como a desbrota, sobre o crescimento da floresta, fornece indicativos sobre sua eficácia.

\subsection{Predições}

(i) $\mathrm{O}$ conhecimento sobre o ciclo de colheita para caixeta, permite uma análise mais acurada sobre a viabilidade ambiental e econômica do manejo de caixetais;

(ii) $\mathrm{O}$ acompanhamento dos caixetais manejados, após a aplicação de práticas silviculturais, permite a avaliação de seus efeitos e de sua eficiência sobre o desenvolvimento da caixeta.

\subsection{Objetivos}

(i) Conhecer a taxa de crescimento de caixetais manejados e inferir sobre o seu ciclo de colheita;

(ii) Verificar a influência da desbrota, prática silvicultural pós-colheita, sobre o crescimento da caixeta e suas implicações sobre a qualidade de fuste;

(iii) Verificar se o ciclo de corte de 12 anos, proposto pela Resolução SMA 11/92 é realmente aplicável para os caixetais manejados;

(iv) Aprimorar o manejo da caixeta e da legislação que o regulamenta, visando a sustentabilidade da atividade. 


\title{
3 CRESCIMENTO E QUALIDADE DE FUSTE DE BROTAÇÕES DE CAIXETA - Tabebuia cassinoides (LAM.) DC. - 8 ANOS APÓS A COLHEITA
}

\author{
Autor RICARDO BERNHARDT
}

Orientador: Prof. Dr. VIRGILIO MAURICIO VIANA

\section{Resumo}

A caixeta - Tabebuia cassinoides (LAM.) DC. - é uma espécie que ocorre nas planícies de inundação da Floresta Atlântica. A atividade apresenta grande importância para a economia do Vale do Ribeira, além disto é uma das únicas espécies arbóreas da Floresta Atlântica com legislação que regulamenta o seu manejo. Uma das principais características da espécie que favorecem seu manejo, é a capacidade de emitir brotações após a colheita. Desta forma, uma das principais práticas silviculturais pós-colheita de seu manejo é a desbrota. Este trabalho teve por objetivo analisar os efeitos da desbrota sobre o desenvolvimento das brotações, assim como sobre aspectos qualitativos dos brotos como, altura da 1- bifurcação e forma de fuste, 8 anos após a colheita. No estudo foram consideradas 224 cepas de caixeta, divididas em 7 blocos ao acaso. Os fatores que influenciam significativamente (5\% probabilidade) o desenvolvimento das brotações, 8 anos após a colheita, são: (i) número de brotos por cepa; (ii) tamanho de cepa; (iii) densidade ao redor da cepa, sendo que a influência do fator rotação não foi significativa. Assumindo apenas o fator número de brotos por cepa, por ser um dos mais significativos e por ser o mais 
facilmente identificado pelos caixeteiros no momento da desbrota. Os tratamentos em que foram deixados 1 e 2 brotos não diferem estatisticamente entre si e apresentam diâmetro médio das brotações de 8,95 cm e 8,37 cm, respectivamente. Enquanto, o tratamento em que foram deixadas 3 e todas as brotações apresentam diâmetro médio de $7,30 \mathrm{~cm}$ e $5,37 \mathrm{~cm}$, respectivamente. A aplicação da desbrota melhorou significativamente a qualidade de fuste, aumentando a altura da $1^{\text {a }}$ bifurcação $\mathrm{e}$ reduzindo a tortuosidade em todos os tratamentos que tiveram desbrota, quando comparada ao tratamento testemunha. Desta forma, a prática silvicultural desbrota é essencial para a melhoria do crescimento e da qualidade das brotações, sendo o número ideal de brotos a serem deixados por cepa, até o momento, é de 2 . O crescimento e a qualidade de fuste das cepas que possuem 2 brotos é o mesmo das cepas com apenas 1 broto, sendo que a vantagem do primeiro, caso a tendência se mantenha, é de que haverá 2 fustes ao final do ciclo ao invés de 1.

Palavras-chave: Tabebuia cassinoides, caixeta, prática silvicultural, desbrota, crescimento, qualidade de fuste 


\title{
GROWTH AND STEM QUALITY OF STUMO SPROUTS OF CAIXETA - Tabebuia cassinoides (LAM.) DC. - 8 YEARS AFTER LOGGING
}

\author{
Author: RICARDO BERNHARDT \\ Adviser: PROF. DR. VIRGILIO MAURICIO VIANA
}

\section{Summary}

Caixeta - Tabebuia cassinoides (LAM.) DC. - is a tree species of swamp forests in the Atlantic Rain Forest. It has a great importance for Vale do Ribeira (São Paulo State) economy and because caixeta is one of the few tree species that in Atlantic Rain Forest that has laws about its management. One of the most important characteristics for management of the specie, is its sprouts capacity after harvest. So sprout thinning is one of the most important silvicultural practices. The objective of this paper is to analyze the effects of sprout thinning on growth and stem quality, such as height of first fork and stem form, 8 years after harvest. The study has 224 caixeta stumps, in 7 blocks hazard distributed. Eight years after logging, the factors that have significant effect (at 5\% probability level) of sprout growth are: (i) number of sprouts left by stump;(ii) stump size; (iii) tree density around the stump, only rotation doesn't have significant effect. Taking upon only the factor number of sprouts left by stump, because its effect is very significant and because this factor is easy to be identified by caixeteiros (people who works with caixeta) in field. The treatments that have 1 and 2 sprouts don't distinguish statistically between them, and after 8 years the sprouts have mean DBH of $8,95 \mathrm{~cm}$ and $8,37 \mathrm{~cm}$, respectively. While the treatments that have 3 and all sprouts have mean DBH of 7,30 cm and $5,37 \mathrm{~cm}$, 
respectively, for the same period. Sprout thinning improves stem quality, increasing the height of first fork and reducing stem sinuosity, when compared with sprouts without thinning. So sprout thinning is essential to improve growth and stem quality of sprouts and the ideal number of sprouts to be left by stump is 2, until now. Growth and stem quality is the same for the stumps that have 2 and 1 sprout and the advantage of the first situation is that in the end of the cutting cycle there'll be 2 stems for harvest instead of 1 , if the trend continue the same.

Key words: Tabebuia cassinoides, caixeta, silvicultural practice, sprout thinning, sprout growth, stem quality 


\subsection{Introdução}

A caixeta - Tabebuia cassinoides (LAM.) DC. é uma espécie arbórea que ocorre exclusivamente nas planícies alagáveis da Mata Atlântica. Apresenta porte mediano atingindo altura em torno de $15 \mathrm{~m}$ e DAP de até 1,00 m, em áreas pouco exploradas (Carvalho, 1994; Lorenzi, 1992). Nos locais onde a caixeta ocorre em alta densidade as florestas são comumente denominadas "caixetais" (Marquesini et al., 2000). A madeira de caixeta apresenta características fisico-mecânicas como baixa densidade, grã-direita, superfície lisa, boa trabalhabilidade e acabamento, que a tornam de excelente qualidade para a produção de tamancos, lápis, artesanato e peças ortopédicas.

A caixeta vem sendo utilizada comercialmente desde da década de 30, sendo o Vale do Ribeira, região sul do Estado de São Paulo, uma das regiões com maior concentração de florestas com caixeta. A atividade foi muito intensa na região, sendo que só no município de Iguape envolveu direta e indiretamente 250 famílias (Diegues, 1991).

A atividade relacionada à extração de caixeta iniciou seu declínio na década de 80, pela entrada no mercado de madeira oriunda de plantações (Pinus sp.), pela intensa exploração dos caixetais da região, baixo grau de planejamento, manejo inadequado da espécie e da baixa eficiência no aproveitamento dos recursos florestais (Diegues, 1991; Nolasco, 2000). A paralisação legal de seu corte foi em 1989, sendo que em 1992 a atividade foi regulamentada pela Resolução SMA 11/92 (Secretaria do Meio Ambiente do Estado de São Paulo), devido às pressões do "movimento dos caixeteiros", pessoas que tradicionalmente trabalhavam na colheita ou no processamento da caixeta, ONG's e instituições de ensino (Marquesini et al., 2000).

Procurando viabilizar o manejo sustentável de caixeta, foram desenvolvidos os projetos "Caixeta" e "Manejo Integrado e Sustentável de Florestas de Caixeta - 
Tabebuia cassinoides - no Vale do Ribeira/SP" (Nolasco, 2000). A partir dos resultados, observou-se que a caixeta apresenta algumas características que favorecem o manejo sustentável, como: (i) alta capacidade de reprodução vegetativa através de brotação de raízes e cepas, dispensando o plantio após a colheita; (ii) possui de pequeno a médio porte, causando menos impacto durante a colheita; (iii) alta dominância de caixeta e baixa diversidade de outras espécies arbóreas; e (iv) a madeira de caixeta possui alto valor de mercado (Viana et al., 1996). O grande vigor da brotação de caixeta, após a colheita, foi observada numa área experimental onde cada cepa emitiu em média 12 brotos (Silva, 2000).

A capacidade da caixeta em regenerar por brotação de cepas é um dos principais fatores a serem considerados no seu manejo. A regeneração por brotação, quando comparada à regeneração por sementes, apresenta um rápido crescimento inicial, em função da reserva de carboidratos remanescente na cepa e pela melhor absorção de água e nutriente, pelo sistema radicular já estabelecido (Reis \& Reis, 1997; Hamilton, 2002 e Rauscher, 2003). A condução de brotações é um sistema de manejo que apresenta as seguintes vantagens (Matthews, 1996):

- É uma prática de fácil aplicação, sendo a produção futura mais confiável e barata que a produção a partir de sementes;

- Normalmente a produção é maior no primeiro ciclo de brotação do que a originada por mudas, para a mesma idade. Apesar disto, pode apresentar queda de produção nas rotações subseqüentes;

- Nos estágios iniciais o desenvolvimento das brotações é mais rápido e apresenta fustes mais retos e com menos nós que as plantas originadas por sementes;

- Onde há mercado para madeira de pequeno diâmetro, a condução da brotação apresenta ciclo menor que os demais sistemas de manejo, em função rápido crescimento inicial. Há menor investimento na produção e retorno mais rápido que os demais sistemas de manejo. Desta forma, a condução da brotação é particularmente apropriada para pequenas propriedades, onde há demanda para madeira de pequeno diâmetro; 
- A variedade de hábitats proporcionada pelos diferentes estágios de desenvolvimento das brotações é benéfico para fauna, sendo seu valor para conservação mais significativo que plantações com idade homogênea.

Em função das características da cadeia produtiva de caixeta na região de Iguape, onde a grande maioria da madeira é proveniente de pequenos proprietários e ainda, pelos resultados positivos do manejo sobre o crescimento das brotações de caixeta 44 meses após a colheita, observados por Silva (2000) é que a continuidade dos estudos sobre a prática silvicultural de desbrota é necessária.

\subsubsection{Objetivos}

(i) Acompanhar o crescimento das brotações 8 anos após a colheita;

(ii) Verificar a influência da desbrota, prática silvicultural pós-colheita, sobre o desenvolvimento e qualidade de fuste das brotações de caixeta;

(iii) Fornecer subsídios para a melhoria do sistema de manejo adotado para a caixeta e da legislação que o regulamenta.

\subsection{Materiais e Métodos}

\subsection{1 Área de estudo}

A área de pesquisa está localizada na Fazenda Retiro, de propriedade do Sr. Minoru Shimabokuro, situada às margens da Rodovia SP-222, bairro do Retiro, Iguape/SP. O caixetal estudado tem área aproximada de 15 ha, sendo que 12 ha foram considerados como área experimental. Parte do caixetal é de segunda rotação, tendo sido colhido pela primeira vez em 1969 e novamente em 1994.

O caixetal estudado é classificado como sendo do estágio sucessional Médio, que se caracteriza por apresentar lençol freático aparente com lâmina d'água não 
permanente, formação florestal não pioneira, dossel superior a $10 \mathrm{~m}$ de altura. A caixeta é a espécie arbórea dominante, apresentando densidade relativa superior a 70\% para os indivíduos acima de $5 \mathrm{~cm}$ de DAP; outras espécies ocorrem em baixa frequiência e densidade. Apresenta muitas epífitas, principalmente bromeliáceas (Silva et al., 1999).

\subsubsection{Delineamento Experimental}

A área foi colhida por uma serraria de Iguape, entre maio e setembro de 1994, para a produção de tamancos. Em função da legislação, Resolução SMA 11/92 e do produto a que se destinou a madeira, o diâmetro mínimo de colheita foi de $15 \mathrm{~cm}$ de DAP. Em julho de 1995, após aproximadamente1 ano da colheita, foram instalados os tratamentos de desbrota do caixetal.

O delineamento experimental foi o de blocos ao acaso, totalizando 7 blocos, dentro dos blocos as cepas foram sorteadas (Figura 1). O experimento foi composto por um total de 224 cepas. 


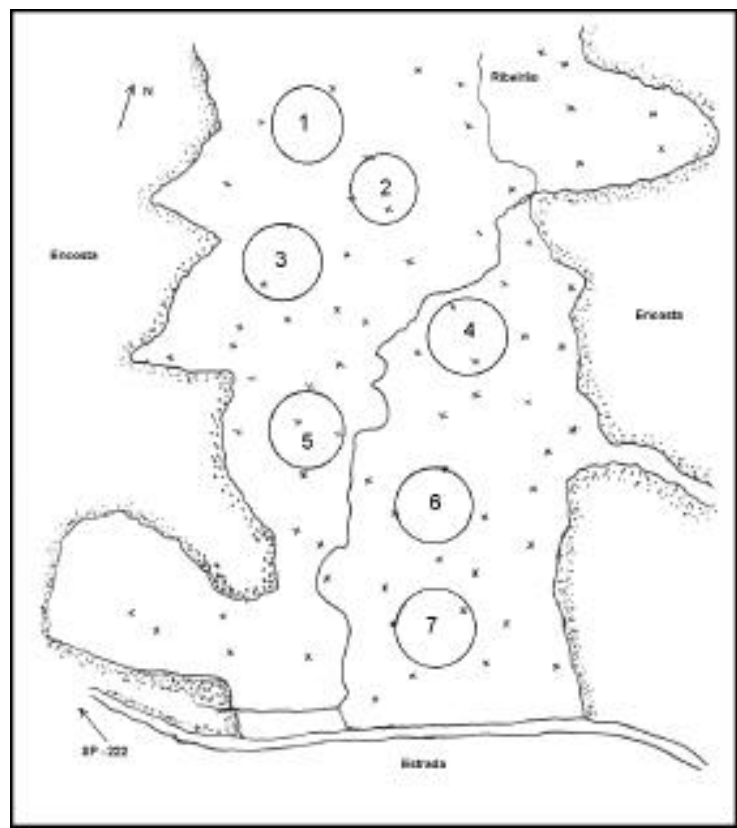

Figura 1 - Croqui da área de pesquisa com a disposição dos blocos do experimento de desbrota (Silva, 2000)

Os tratamentos inicialmente instalados levaram em consideração 4 fatores que interferem no crescimento das brotações de caixeta, conforme Tabela 1. Os fatores investigados para verificar sua influência sobre o desenvolvimento das brotações de caixeta foram: (i) número de brotos por cepa; (ii) tamanho de cepa; (iii) rotação, e; (iv) densidade arbórea ao redor da cepa.

Tabela 1. Fatores, níveis e respectivos tratamentos para os experimentos com brotação (Silva, 2000)

\begin{tabular}{lll}
\hline Fatores & Níveis & Definições \\
\hline Número de brotos por cepa & 4 & $1,2,3$ e todos os brotos (testemunha) \\
Tamanho de cepa & 2 & Acima e abaixo de $17,5 \mathrm{~cm}$ de DAP \\
Rotação & 2 & Cepas de $1^{\circ}$ e $2 \stackrel{\circ}{\circ}$ corte \\
Densidade & 2 & "Alta" e "média" densidade \\
Número de tratamentos & $\mathbf{3 2}$ & \\
\hline
\end{tabular}




\subsubsection{Coleta de dados}

A presente pesquisa é continuação do trabalho desenvolvido por Silva (2000), que após a colheita da área, acompanhou o desenvolvimento das brotações do experimento de desbrota por 44 meses. As medições foram realizadas em intervalos variáveis, principalmente em função da disponibilidade de recursos para o desenvolvimento da atividade, conforme Tabela 2.

Tabela 2. Época de instalação e coleta dos dados do experimento de brotação

\begin{tabular}{ll}
\hline Atividade & Período \\
\hline Colheita da área & Junho a setembro de 1994 \\
Instalação do experimento de desbrota & julho de 1995 \\
Coleta de dados & julho de 1995 \\
& janeiro de 1996 \\
& fevereiro de 1997 \\
& abril de 1998 \\
& abril de 2001 \\
& julho de 2002 \\
\hline
\end{tabular}

\subsubsection{Qualidade de fuste}

Em função do longo período de acompanhamento do desenvolvimento das brotações na Fazenda Retiro, de 1995 a 2002, procurou-se verificar se há influência dos diferentes tratamentos de desbrota sobre a qualidade de fuste das brotações. Para isto foram coletadas informações quantitativas e qualitativas, como: (i) altura da 1a bifurcação, e; (ii) forma do fuste.

A altura da 1'- bifurcação dos brotos das cepas experimentais, é um fator importante para a qualidade, visto que o volume aproveitável de madeira para as colheitas futuras tem relação direta com o cumprimento de fuste. 
A forma do fuste é outro fator importante relacionado ao aproveitamento de madeira nas colheitas futuras, pois quanto mais retilíneo o fuste, melhor será o aproveitamento da madeira. Para avaliar a forma dos fustes assumiram-se 3 classes de tortuosidade, descritas a seguir:

(i) baixa - o fuste é praticamente retilíneo (valor 3);

(ii) média - o fuste apresenta pouca irregularidade. A forma é afetada pela competição entre brotos na cepa e pela elevada quantidade de galhos (valor $2)$;

(iii) alta - o fuste é bastante irregular, sendo comum a presença de "cotovelo". Isto ocorre possivelmente em função da competição entre brotos e pela ação de cipós, que tombam as brotações (valor 1).

Os valores assumidos para cada uma das classes de tortuosidade foram utilizados para realizar um teste de comparações de médias, teste Tukey, como maneira de comparar o efeito da desbrota sobre a forma de fuste.

Como a caixeta é uma espécie que naturalmente apresenta tortuosidade elevada, a separação em classes levou em consideração esta característica própria da espécie.

\subsection{Resultados e Discussão}

As análises estatísticas dos experimentos de brotação foram realizadas com o programa estatístico S-Plus 2000.

\subsubsection{Crescimento das brotações}

O primeiro passo foi a verificação dos fatores que tem influência significativa no crescimento das brotações, no caso foi utilizado apenas o parâmetro diâmetro. Observou-se que os fatores "número de brotos" deixados por cepa, "densidade" e 
"tamanho da cepa" apresentaram influência significativa, ao nível de 5\% de probabilidade, sobre o crescimento das brotações (Tabela 3). Já o fator "rotação" não apresentou influência significativa sobre o crescimento das brotações (Tabela 3), aos 92,4 meses após a colheita. Silva (2000) acompanhando o crescimento das brotações durante 44 meses, após a colheita, observou a mesma tendência do fator "rotação" não influir significativamente no crescimento das brotações. Isto aparentemente pode indicar que não há redução no vigor das brotações de caixeta com o aumento da idade das cepas, como é observado no caso de plantios de Eucalyptus sp. em que a produção sofre uma redução em torno de $20 \%$ entre uma rotação e outra (Küntzel et al., 1987).

Tabela 3. Resultado da ANAVA, para a variável DAP, aos 8 anos após a colheita

\begin{tabular}{|c|c|c|c|c|c|}
\hline Fatores & G.L. & $\begin{array}{l}\text { Soma de } \\
\text { quadrados }\end{array}$ & $\begin{array}{l}\text { Quadrado } \\
\text { médio }\end{array}$ & Valor F & $\mathbf{P R}(\mathbf{F})$ \\
\hline $\begin{array}{l}\text { Número de } \\
\text { brotos }\end{array}$ & 3 & 1231,43 & 410,48 & 125,041 & 0,000000 \\
\hline Idade & 1 & 11234,13 & 11234,43 & 3422,181 & 0,00000 \\
\hline Rotação & 1 & 4,91 & 4,91 & 1,496 & 0,22141 \\
\hline Densidade & 1 & 122,96 & 122,96 & 37,184 & 0,00000 \\
\hline $\begin{array}{l}\text { Tamanho } \\
\text { de cepa }\end{array}$ & 1 & 234,75 & 234,75 & 71,510 & 0,00000 \\
\hline
\end{tabular}

Outro fator analisado que influenciou significativamente o crescimento em DAP foi a "idade" da brotação, que corresponde ao período após a colheita da área. Isto se deve ao fato que o crescimento das brotações é função direta do tempo decorrido após a colheita.

Apesar dos fatores "densidade" e "tamanho de cepa" terem apresentado influência significativa no crescimento das brotações, neste trabalho optou-se por restringir as análises de crescimento e incremento apenas para o fator "número de brotos". A opção foi baseada no fato que o "número de brotos" deixados por cepa, é o fator mais facilmente identificado pelos caixeteiros no campo, responsáveis pela 
realização da desbrota, e pela sua influência extremamente significativa no desenvolvimento das brotações.

O diâmetro médio por tratamento é maior para o tratamento em que foi deixado apenas 1 broto, para todos os anos de coleta (Tabela 4). Apesar disto, os valores médios de diâmetro entre os tratamentos 1 e 2 brotos não diferem estatisticamente entre si, ou seja estes tratamentos apresentaram mesmo padrão de desenvolvimento, durante o período analisado. Outro ponto interessante é que no início do experimento em 1995, não havia diferença estatística entre os tratamentos, possivelmente pelo fato de que inicialmente a competição não estava estabelecida entre os brotos de uma mesma cepa e nem com os indivíduos ao redor da cepa, em função da abertura do dossel pela colheita. A partir do estabelecimento da competição entre brotos e os indivíduos ao redor da cepa, foi que os tratamentos começaram a diferir estatisticamente, por volta de 1997, 3 anos após a colheita (Tabela 4).

Tabela 4. Valores médios de DAP $(\mathrm{cm})$ por tratamento, por ano de coleta de dados

\begin{tabular}{ccccccc}
\hline Tratamento & $\begin{array}{c}\text { DAP } \\
\mathbf{1 9 9 5}\end{array}$ & $\begin{array}{c}\text { DAP } \\
\mathbf{1 9 9 6}\end{array}$ & $\begin{array}{c}\text { DAP } \\
\mathbf{1 9 9 7}\end{array}$ & $\begin{array}{c}\text { DAP } \\
\mathbf{1 9 9 8}\end{array}$ & $\begin{array}{c}\text { DAP } \\
\mathbf{2 0 0 1}\end{array}$ & $\begin{array}{c}\mathbf{D A P} \\
\mathbf{2 0 0 2}\end{array}$ \\
\hline $\begin{array}{c}1 \text { broto por } \\
\text { cepa }\end{array}$ & $1,98^{\mathrm{a}}$ & $3,07^{\mathrm{a}}$ & $4,46^{\mathrm{a}}$ & $5,88^{\mathrm{a}}$ & $8,08^{\mathrm{a}}$ & $8,95^{\mathrm{a}}$ \\
$\begin{array}{c}\text { brotos por } \\
\text { cepa }\end{array}$ & $1,95^{\mathrm{a}}$ & $2,95^{\mathrm{a}}$ & $4,31^{\mathrm{a}}$ & $5,59^{\mathrm{a}}$ & $7,51^{\mathrm{a}}$ & $8,37^{\mathrm{a}}$ \\
$\begin{array}{c}\text { brotos por } \\
\text { cepa }\end{array}$ & $1,77^{\mathrm{a}}$ & $2,77^{\mathrm{b}}$ & $3,86^{\mathrm{b}}$ & $4,90^{\mathrm{b}}$ & $6,41^{\mathrm{b}}$ & $7,30^{\mathrm{b}}$ \\
$\begin{array}{c}\text { Todos } \\
\text { brotos }\end{array}$ & $1,78^{\mathrm{a}}$ & $2,87^{\mathrm{ab}}$ & $2,56^{\mathrm{c}}$ & $3,77^{\mathrm{c}}$ & $5,40^{\mathrm{c}}$ & $5,73^{\mathrm{c}}$ \\
& & & & & &
\end{tabular}

Valores seguidos de mesma letra não diferem significativamente entre si ao nível de $5 \%$ de probabilidade (teste de Tukey) 


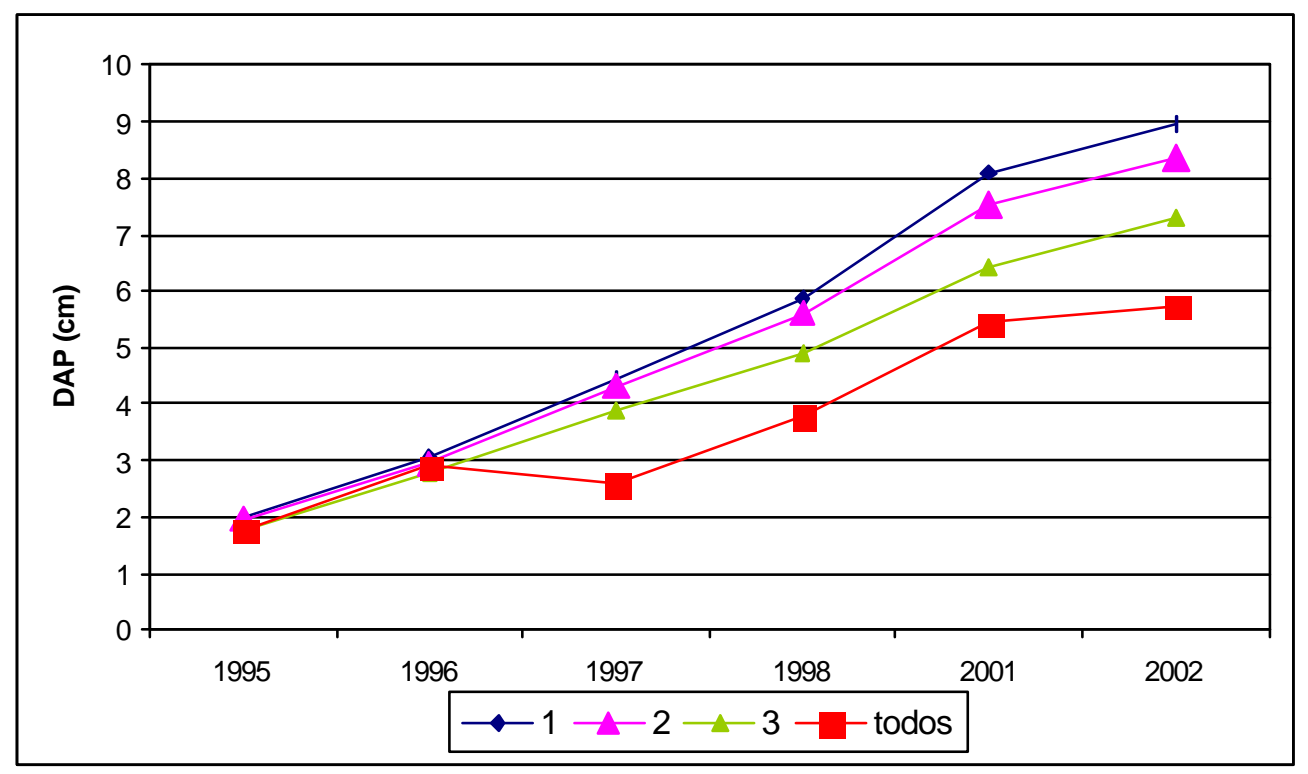

Figura 2 - Diâmetro médio de fuste por tratamento por ano de coleta de dados

Para a variável altura média o comportamento foi semelhante ao da variável DAP. Ao final de 8 anos de acompanhamento do experimento, observou-se uma tendência do tratamento com 2 brotos por cepa, apresentar um desenvolvimento superior aos demais tratamentos, porém não diferindo estatisticamente do tratamento com 1 broto (Tabela 5). A tendência observada de não haver diferença estatística entre os tratamentos, nos primeiros anos de acompanhamento até o estabelecimento de competição entre brotos, se mantêm. 
Tabela 5. Valores médios de altura dos brotos (m) por tratamento, por ano de coleta de dados

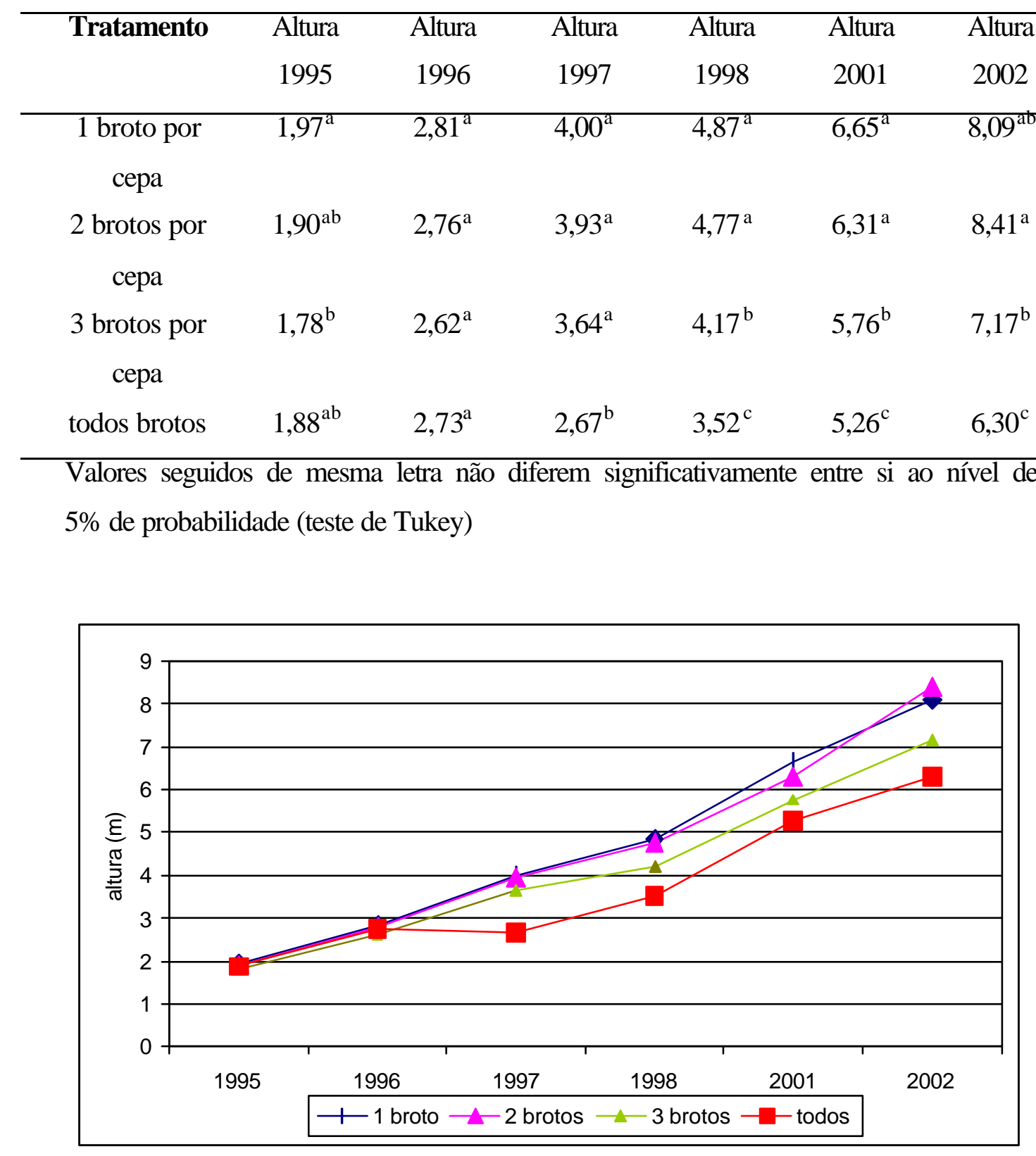

Figura 3 - Altura média de fuste por tratamento por ano de coleta de dados

Através das figuras 2 e 3, que representam os valores médios observados de diâmetro e altura de fuste, respectivamente, observa-se que no ano de 1997, há uma 
redução dos valores médios do tratamento testemunha (todos os brotos), isto de deve ao fato que nos anos de 1995 e 1996 eram medidos apenas os 3 maiores brotos das cepas que compunham este tratamento. A partir de 1997, foram coletadas informações de todos os brotos das cepas testemunha, pelo fato que a medição apenas dos 3 maiores brotos, não representava adequadamente a competição estabelecida entre as brotações e, conseqüientemente seu efeito sobre o desenvolvimento de todas as brotações existentes na cepa.

Além dos valores médios observados para os tratamentos foram analisados os incrementos periódicos anuais para as variáveis diâmetro e altura das brotações. Assim como para a variável DAP, o Incremento Periódico Anual em diâmetro não apresentou diferença significativa entre tratamentos no início do experimento (Tabela 6). Outro ponto a ser observado é que não houve diferença estatisticamente significativa entre os tratamentos em que foram deixados 1 e 2 brotos, durante o período analisado.

Já os tratamentos em que foram deixados 3 e todos os brotos, não apresentaram incrementos que diferem estatisticamente entre si até o ano de 2001, ou seja apresentaram o mesmo padrão de crescimento, durante os 81 primeiros meses de acompanhamento após a colheita (Tabela 6). Somente no período de 2001 a 2002 é que o incremento dos tratamentos com 3 e todos os brotos diferiram estatisticamente entre si.

Todos os tratamentos apresentaram acréscimo no Incremento Periódico Anual entre os anos de 1994 e 1996 e houve decréscimo entre os anos de 1996 e 2001 . O decréscimo do incremento possivelmente ocorreu em função da competição por luz entre cepas e no caso das cepas que possuem mais de 1 broto, também por competição entre os brotos dentro da cepa (Figura 4). Entre 2001 e 2002, o Incremento Periódico Anual apresentou um acréscimo, porém foi inferior aos valores de incremento observados para os períodos anteriores. Durante o período de 1998 a 2001, houve uma queda mais acentuada no incremento médio anual (Figura 4). 
Tabela 6. Incremento Médio Anual em diâmetro (cm/fuste/ano), por tratamento

\begin{tabular}{cccccccc}
\hline \multicolumn{7}{c}{ Incremento Periódico Anual em diâmetro (cm/fuste/ano) } \\
\hline Tratamento & $\mathbf{1 9 9 4 -}$ & $\mathbf{1 9 9 5}$ & $\mathbf{1 9 9 6}-$ & $\mathbf{1 9 9 7}$ & $\mathbf{1 9 9 8}$ & $\mathbf{2 0 0 0 1}$ & Média \\
& $\mathbf{9 5}$ & $\mathbf{- 9 6}$ & $\mathbf{9 7}$ & $\mathbf{- 9 8}$ & $\mathbf{- 0 1}$ & $\mathbf{- 0 2}$ & \\
$\begin{array}{c}\text { 196 proto por } \\
\text { cepa }\end{array}$ & $1,98^{\mathrm{a}}$ & $2,23^{\mathrm{a}}$ & $1,38^{\mathrm{a}}$ & $1,15^{\mathrm{a}}$ & $0,73^{\mathrm{a}}$ & $0,91^{\mathrm{a}}$ & 1,20 \\
$\begin{array}{c}\text { brotos por } \\
\text { cepa }\end{array}$ & $1,95^{\mathrm{a}}$ & $2,03^{\mathrm{a}}$ & $1,31^{\mathrm{a}}$ & $1,02^{\mathrm{a}}$ & $0,63^{\mathrm{a}}$ & $0,86^{\mathrm{a}}$ & 1,11 \\
$\begin{array}{c}\text { brotos por } \\
\text { cepa }\end{array}$ & $1,77^{\mathrm{a}}$ & $1,87^{\mathrm{a}}$ & $1,07^{\mathrm{b}}$ & $0,87^{\mathrm{b}}$ & $0,47^{\mathrm{b}}$ & $0,89^{\mathrm{a}}$ & 0,99 \\
$\begin{array}{c}\text { Todos } \\
\text { brotos }\end{array}$ & $1,78^{\mathrm{a}}$ & $1,89^{\mathrm{a}}$ & $1,19^{\mathrm{ab}}$ & $0,70^{\mathrm{b}}$ & $0,49^{\mathrm{b}}$ & $0,65^{\mathrm{b}}$ & 0,95 \\
\hline
\end{tabular}

Valores seguidos de mesma letra não diferem significativamente entre si ao nível de $5 \%$ de probabilidade (teste de Tukey)

Caso o incremento médio do período de acompanhamento, 8 anos se mantenha constante em 1,16 cm/fuste/ano (média dos tratamentos 1 e 2 brotos por cepa), seriam necessários 12,9 anos para um broto atingir DAP de $15 \mathrm{~cm}$ (diâmetro mínimo de colheita). Silva (2000), considerando o incremento diamétrico das brotações até os 44 meses após a desbrota como sendo constante, observou que seriam necessários 8,9 anos para um broto atingir $15 \mathrm{~cm}$ DAP. Como se pode observar na Tabela 6 e Figura 4, há uma tendência de queda no incremento anual, com isto possivelmente o tempo necessário para um broto atingir $15 \mathrm{~cm}$ de DAP deva ser superior a 12,9 anos. 


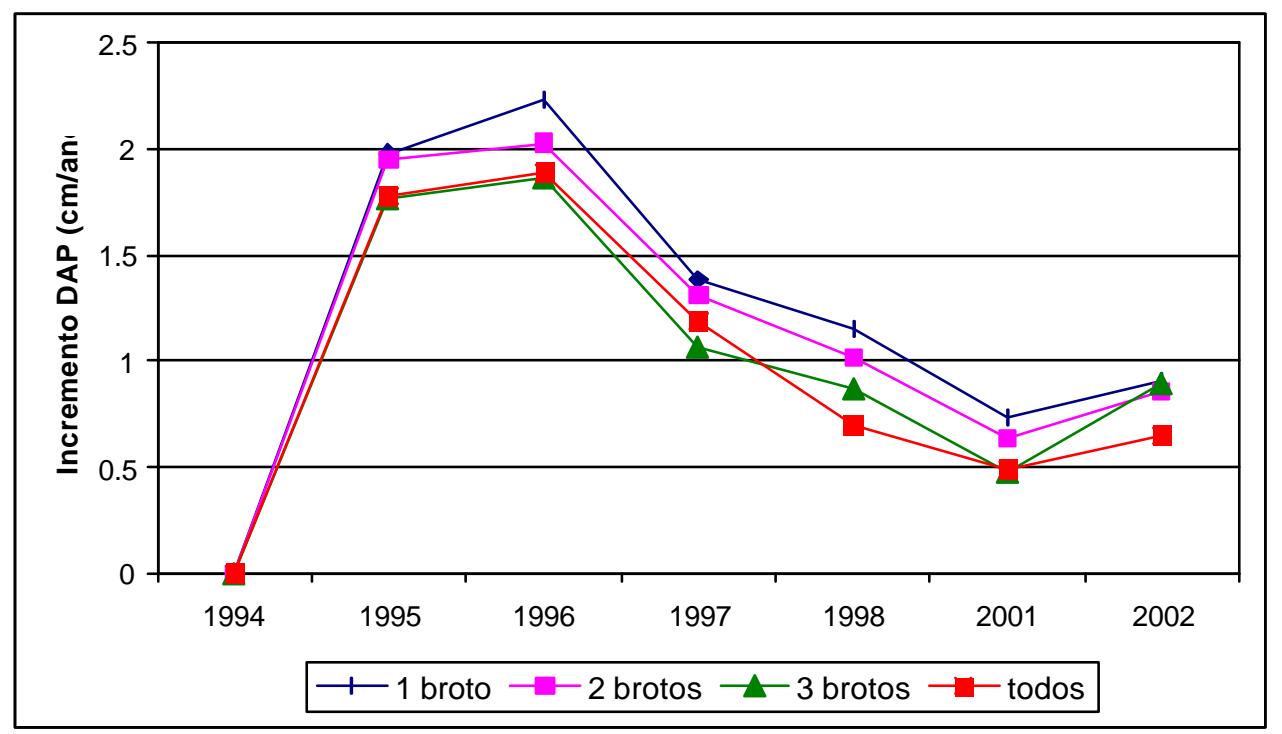

Figura 4 - Incremento Médio anual em diâmetro (cm/fuste/ano) por tratamento de desbrota

O incremento periódico médio em altura apresenta padrões semelhantes ao apresenta do pela variável diâmetro, porém não com uma tendência tão nítida de que os tratamentos com menos brotos apresentaram incrementos superiores que os que possuem mais brotos (Tabela 7 e Figura 5). Apesar de não ser estatisticamente significativa a diferença entre os tratamentos com 1 e 2 brotos por cepa, para o incremento em altura o tratamento com 2 brotos foi superior ao com 1 broto e significativamente superior aos demais. 
Tabela 7. Incremento Médio Anual em altura por tratamento

Incremento Periódico Anual em altura (m/fuste/ano)

\begin{tabular}{cccccccc}
\hline Tratamento & $\mathbf{1 9 9 4 -}$ & $\mathbf{1 9 9 5}$ & $\mathbf{1 9 9 6}$ & $\mathbf{1 9 9 7 -}$ & $\mathbf{1 9 9 8}-$ & $\mathbf{2 0 0 1}-$ & Média \\
& $\mathbf{9 5}$ & $\mathbf{- 9 6}$ & $\mathbf{- 9 7}$ & $\mathbf{9 8}$ & $\mathbf{0 1}$ & $\mathbf{0 2}$ & \\
\hline $\begin{array}{c}1 \text { broto por } \\
\text { cepa }\end{array}$ & $1,97^{\mathrm{a}}$ & $1,63^{\mathrm{a}}$ & $1,18^{\mathrm{a}}$ & $0,80^{\mathrm{ab}}$ & $0,61^{\mathrm{a}}$ & $1,43^{\mathrm{ab}}$ & 1,09 \\
$\begin{array}{c}\text { brotos por } \\
\text { cepa }\end{array}$ & $1,90^{\mathrm{ab}}$ & $1,63^{\mathrm{a}}$ & $1,15^{\mathrm{a}}$ & $0,87^{\mathrm{a}}$ & $0,52^{\mathrm{a}}$ & $1,55^{\mathrm{a}}$ & 1,09 \\
$\begin{array}{c}\text { brotos por } \\
\text { cepa }\end{array}$ & $1,76^{\mathrm{b}}$ & $1,39^{\mathrm{a}}$ & $1,03^{\mathrm{a}}$ & $0,64^{\mathrm{bc}}$ & $0,50^{\mathrm{a}}$ & $1,48^{\mathrm{a}}$ & 0,97 \\
$\begin{array}{c}\text { Todos brotos } \\
\text { boto }\end{array}$ & $1,88^{\mathrm{ab}}$ & $1,56^{\mathrm{a}}$ & $1,16^{\mathrm{a}}$ & $0,61^{\mathrm{c}}$ & $0,54^{\mathrm{a}}$ & $1,22^{\mathrm{b}}$ & 0,99
\end{tabular}

Valores seguidos de mesma letra não diferem significativamente entre si ao nível de 5\% de probabilidade (teste de Tukey)

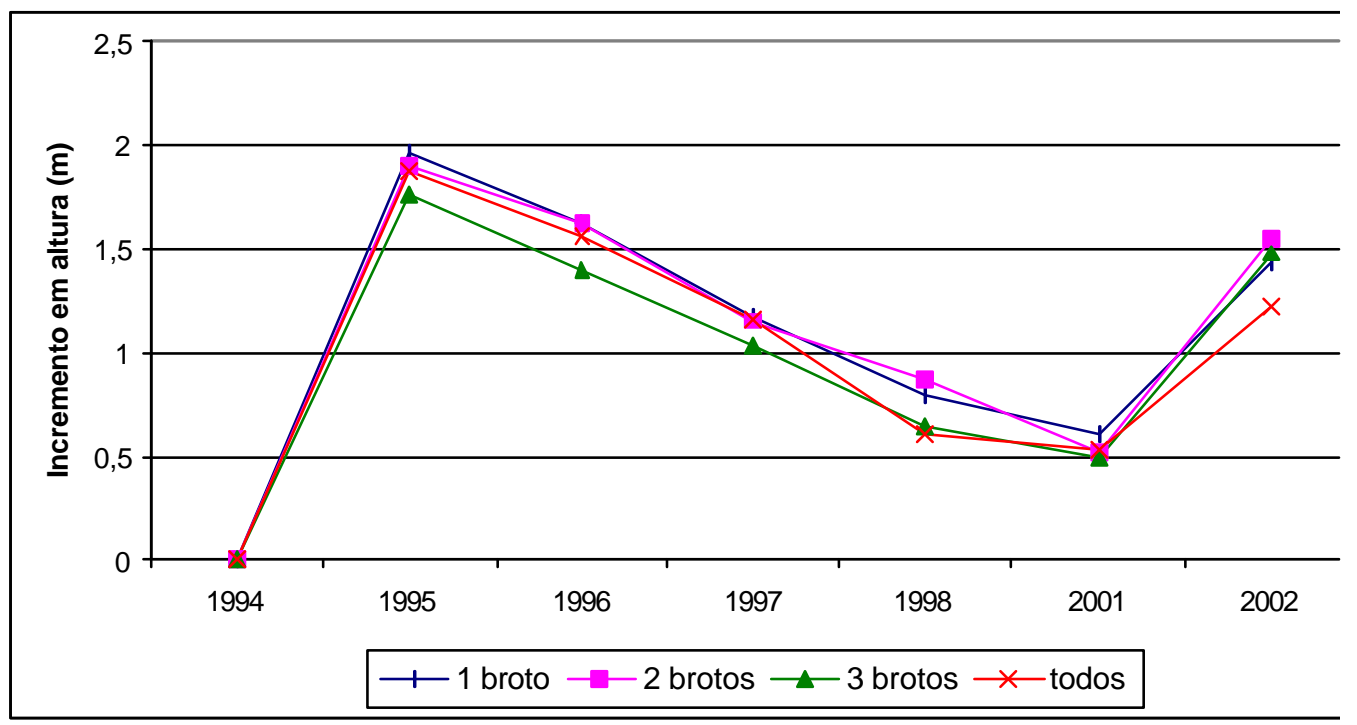

Figura 5 - Incremento Médio anual em altura (m/fuste/ano) por tratamento de desbrota

O Incremento Anual para as variáveis diâmetro e altura apresentou um aumento no último período observado, entre os anos de 2001 e 2002. Isto pode ser devido ao fato das brotações estarem atingindo a altura do dossel, e desta forma houve uma 
redução na competição por luz entre a caixeta e os indivíduos ao redor da cepa, acarretando num acréscimo do Incremento Anual.

Para as variáveis diâmetro e altura e seus respectivos incrementos, não houve diferença significativa entre os tratamentos com 1 e 2 brotos por cepa, 8 anos após a colheita. Entre os tratamentos em que foram deixados 3 e todos os brotos observaram-se diferenças estatísticas significativas em alguns dos períodos observados, mas de modo geral apresentam o mesmo padrão de desenvolvimento, fato que é corroborado pelas observações de campo.

De acordo com as informações obtidas de crescimento e incremento dos diferentes tratamentos e observações de campo, o número mais indicado de brotos a serem deixados por cepa, até o momento, são 2. Devido ao fato de apresentar desenvolvimento superior aos tratamentos em que foram deixados 3 e todos os brotos e por não ter apresentado diferença significativa do tratamento em que foi deixado apenas 1 broto. Caso o comportamento do desenvolvimento do tratamento com 2 brotos se mantenha similar ao de 1 broto, a vantagem do primeiro é que ao final do ciclo seriam colhidos 2 fustes ao invés de 1. Hamilton (2000) recomenda que devam ser deixados de 1 a 2 brotos por cepa de eucalipto para a produção de madeira para serraria, ou seja a mesma quantidade para a caixeta, que visa também a produção de madeira para serraria.

\subsubsection{Qualidade de fuste}

Como variáveis relacionadas à qualidade de fuste de caixeta, foram consideradas duas informações de fácil obtenção no campo, a primeira foi a altura da primeira bifurcação e a segunda, a forma/tortuosidade dos fustes. Para altura da primeira bifurcação, o maior valor médio observado foi de 4,89 $\mathrm{m}$ para o tratamento de 1 broto, que foi $0,80 \mathrm{~m}$ superior à altura média observada para o tratamento em que foram deixados todos os brotos (Tabela 7). Como tradicionalmente o comprimento de tora para caixeta é em torno de $1,00 \mathrm{~m}$, significa que no tratamento em que foi 
deixado apenas 1 broto haveria praticamente uma tora a mais que o tratamento que não sofreu desbrota. Os tratamentos que receberam a desbrota apresentaram os maiores valores máximos para a altura da 1a bifurcação e também a maior variabilidade (Tabela 7).

Tabela 8. Valor médio, máximo e mínimo de altura da primeira bifurcação para brotações de caixeta 8 anos após a colheita, Iguape/SP

\begin{tabular}{ccccc}
\hline Tratamento & $\begin{array}{c}\text { Altura média } \\
\text { da 1 }\end{array}$ & $\begin{array}{c}\text { Valor } \\
\text { máximo }(\mathbf{m})\end{array}$ & $\begin{array}{c}\text { Valor } \\
\text { mínimo }(\mathbf{m})\end{array}$ & $\begin{array}{c}\text { Desvio } \\
\text { padrão }\end{array}$ \\
\hline 1 broto & $4,89^{\mathrm{a}}$ & 8,00 & 1,00 & 1,51 \\
2 brotos & $4,69^{\mathrm{a}}$ & 9,00 & 1,50 & 1,41 \\
3 brotos & $4,42^{\mathrm{a}}$ & 8,5 & 1,70 & 1,48 \\
Todos brotos & $4,09^{\mathrm{b}}$ & 7,50 & 1,20 & 1,30
\end{tabular}

Valores seguidos de mesma letra não diferem significativamente entre si ao nível de $5 \%$ de probabilidade (teste de Tukey)

De acordo com a tabela 7, observa-se que a aplicação de desbrota contribuiu positivamente para aumentar a altura média da primeira bifurcação nos fustes de caixeta. A princípio era esperado que os tratamentos em que foram deixados 3 e todos os brotos, apresentassem maior altura da primeira bifurcação, em função da competição por luz, que acarretaria num maior crescimento em altura e menor copa, e conseqüentemente maior altura da la bifurcação. Enquanto que os tratamentos em que foram deixados 1 e 2 brotos apresentassem menor altura da la bifurcação em função da menor competição por luz. Entretanto observou-se que não houve diferença significativa para a altura da $1^{\text {a }}$ bifurcação entre os tratamentos em que foi feita a desbrota, apenas entre estes e a testemunha.

Além do aumento da altura da $\mathrm{F}$ bifurcação, observa-se um efeito positivo da desbrota em relação à forma de fuste da caixeta. Os tratamentos em que foram 
deixados 1 e 2 brotos por cepa apresentaram maior proporção de fustes com baixa tortuosidade $43 \%$ e $26,3 \%$, respectivamente, enquanto que os tratamentos que foram deixados 3 e todos os brotos apresentaram maior proporção de fustes coma alta tortuosidade $31,3 \%$ e $30,6 \%$, respectivamente (Tabela 8 ).

Tabela 9. Proporção de fustes por classe de tortuosidade

\begin{tabular}{lccc}
\hline Tratamento & $\begin{array}{c}\text { Baixa } \\
\text { tortuosidade }(\boldsymbol{\%})\end{array}$ & $\begin{array}{c}\text { Média } \\
\text { tortuosidade }(\boldsymbol{\%})\end{array}$ & $\begin{array}{c}\text { Alta tortuosidade } \\
(\boldsymbol{\%})\end{array}$ \\
\hline 1 broto & 43 & 32,9 & 24,1 \\
2 brotos & 26,3 & 50,9 & 22,8 \\
3 brotos & 22,6 & 46,1 & 31,3 \\
todos brotos & 23,4 & 46 & 30,6 \\
\hline
\end{tabular}

Assumindo valores numéricos para cada uma das classes de tortuosidade, sendo valor 3 para a classe de baixa tortuosidade, 2 para a classe de média tortuosidade e 1 para classe de alta tortuosidade, foi realizado o teste de Tukey, para comparação das médias encontradas (Tabela 9). Como se assumiu maior valor para a classe com menor tortuosidade e menor valor para a classe de maior tortuosidade, quanto maior o valor observado menor a tortuosidade.

Tabela 10. Resultado do teste de Tukey para comparação da influência da desbrota sobre a qualidade de fuste

\begin{tabular}{ccc}
\hline Tratamento & Tortuosidade média & Fustes observados \\
\hline 1 broto por cepa & $2,19^{\mathrm{a}}$ & 78 \\
2 brotos por cepa & $2,04^{\mathrm{ab}}$ & 166 \\
3 brotos por cepa & $1,92^{\mathrm{b}}$ & 237 \\
todos brotos & $1,92^{\mathrm{b}}$ & 444
\end{tabular}

Valores seguidos de mesma letra não diferem significativamente entre si ao nível de 5\% de probabilidade (teste de Tukey) 
Pelo teste de Tukey, observa-se que os tratamentos com 1 e 2 brotos por cepa apresentaram melhor forma de fuste, porém o tratamento de 2 brotos não difere estatisticamente dos tratamentos com 3 e todos os brotos. Nos tratamentos com mais brotos, a maior tortuosidade pode ser devido aos seguintes fatores observados em campo como: (i) maior incidência de cipós nestes tratamentos, por haver maior área de apoio e o peso dos cipós tomba as brotações; e; (ii) maior competição por luz entre os brotos, o que faz com que os brotos marginais da cepa se inclinem para buscar luz.

Pelos resultados obtidos, observa-se que a desbrota além de apresentar ganhos significativos do ponto de vista quantitativo, melhorando o crescimento das brotações, apresenta também ganho significativo na questão qualitativa relacionada aos fustes de caixeta. Isto indica que a realização da desbrota é essencial para o manejo de caixetais pois irá melhorar o aproveitamento e o rendimento de madeira nas colheitas futuras.

\subsection{Conclusões}

As cepas que apresentaram maior diâmetro médio ao fim de 8 anos foram aquelas com apenas um 1 broto, seguida das cepas com 2 brotos, os valores observados foram de 8,95 e $8,37 \mathrm{~cm}$, respectivamente. Os dois tratamentos apresentaram comportamento similar, não havendo diferença significativa ao nível de $5 \%$ de probabilidade. Os tratamentos em que foram deixados 3 e todos os brotos, apresentaram desenvolvimento significativamente inferior aos tratamentos com 1 e 2 brotos.

$\mathrm{Na}$ análise qualitativa dos fustes, para os parâmetros altura da $1^{\underline{a}}$ bifurcação e forma de fuste, não houve diferença significativa entre os tratamentos que receberam desbrota. A diferença foi observada entre os tratamentos com desbrota e a testemunha, sem desbrota. Ou seja a aplicação da desbrota contribuiu significativamente para a melhoria da qualidade de fuste, em função do aumento da altura da $1^{\underline{a}}$ bifurcação e pela diminuição da tortuosidade dos fustes, o que 
representará em colheitas futuras maior rendimento e aproveitamento dos recursos florestais.

De acordo com os resultados quantitativos e qualitativos observados 8 anos após a colheita da área, o número de brotos a serem deixados por cepa deve ser de 1 a 2. Como os tratamentos com 1 e 2 brotos apresentam até o momento a mesma performance quantitativa e qualitativa, o número de brotos mais indicado é de 2 por cepa, pois caso a tendência observada se mantenha até o final do ciclo, seriam colhidos 2 fustes ao invés de 1 . 


\title{
4 INCREMENTO VOLUMÉTRICO DE DOIS CAIXETAIS MANEJADOS NO MUNICÍPIO DE IGUAPE/SP
}

\author{
Autor: RICARDO BERNHARDT \\ Orientador: Prof. Dr. VIRGILIO MAURICIO VIANA
}

\section{Resumo}

Os caixetais são utilizados comercialmente desde a década de 30, porém a atividade só foi regulamentada em 1992 através da Resolução SMA 11/92, da Secretaria do Meio Ambiente do Estado de São Paulo. Esta Resolução assume como ciclo de colheita para a caixeta o período de 12 anos. Este trabalho busca conhecer o incremento em volume de caixetais manejados e a partir destas informações fazer inferência sobre o ciclo de colheita para caixeta, verificando se o ciclo estabelecido por lei é aplicável. Foi feitos o acompanhamento do Inventário Florestal em duas áreas, Fazenda Retiro com 50 parcelas e Fazenda Cindumel com 46 parcelas (10 x 20m). O Incremento Médio Anual foi de $3,215 \pm 0,366 \mathrm{~m}^{3} / \mathrm{ha} /$ ano para a Fazenda Retiro e $5,557 \pm 0,598 \mathrm{~m}^{3} / \mathrm{ha} /$ ano para a Fazenda Cindumel. Observou-se que a intensidade de colheita nas áreas foi superior a $50 \%$ do volume de madeira passível de colheita e que nas áreas próximas às rotas de extração a intensidade foi maior, chegando a 94\%. Isto acarretou numa redução de até 54\% do IMA, nas áreas em que a intensidade de colheita foi superior a 75\%, em relação às demais. $\mathrm{O}$ Intervalo de Confiança para o ciclo de colheita estimado para caixetais manejados variou de 12,9 a 17,6 anos. Desta forma, se faz necessária a revisão da 
Resolução SMA 11/92, em relação ao ciclo de colheita e à inclusão de um limite de intensidade de colheita para a caixeta.

Palavras-chave: caixeta, Tabebuia cassinoides, manejo florestal, ciclo de colheita, incremento volumétrico 


\title{
VOLUMETRIC INCREMENT OF TWO MANAGED CAIXETAIS IN IGUAPE/SP
}

\author{
Author: RICARDO BERNHARDT \\ Adviser: Prof. Dr. VIRGILIO MAURICIO VIANA
}

\section{Summary}

Caixetais have been exploited since the 30's, but only in 1992 that the activity was regulated by Resolution 11/92 of the Environmental Secretary of São Paulo State. This Resolution assumes 12 years as the harvest cycle for caixeta. The objective of this paper is to know the caixetais volumetric increment and make inferences about the harvest cycle, comparing with the cycle established by law. The data came from the Forest Inventory of 2 experimental areas, Retiro Farm (50 samples of $200 \mathrm{~m}^{2}$ ) and Cindumel Farm (46 samples of $200 \mathrm{~m}^{2}$ ).

The Mean Annual Increment (MAI) was 3,215 \pm 0,366 $\mathrm{m}^{3} / \mathrm{ha} / \mathrm{ano}$ for Retiro Farm and 5,557 $\pm 0,598 \mathrm{~m}^{3} / \mathrm{ha} /$ ano for Cindumel Farm. The harvest intensity was over $50 \%$ of the amount harvestable wood; the intensity was higher near the extraction routes, reaching $94 \%$. Thus caused a reduction of $54 \%$ in MAI, where the harvest intensity was higher than $75 \%$. The estimated harvest cycle for managed caixetais has Confident Interval from 12,9 to 17,6 years. Thus it's essential to review the harvest cycle proposed by Resolution 11/92 and includes a limit for harvest intensity for caixetal management.

Key words: caixeta, Tabebuia cassinoides, forest management, harvest cycle, volumetric increment 


\subsection{Introdução}

Nas planícies de inundação da Mata Atlântica ocorre a caixeta, Tabebuia cassinoides (Lam.) DC. - Bignoniaceae, uma espécie arbórea de pequeno a médio porte, atingindo em torno de 15 metros de altura, com copa normalmente pequena e de formato arredondado (Carvalho, 1994; Lorenzi, 1992). Nos locais onde a caixeta ocorre com dominância superior a 50\%, as florestas são comumente denominadas "caixetais" (Silva, 2000).

A utilização comercial da caixeta é feita desde a década de 30 e representou importante base da economia para a população do Vale do Ribeira. Seu principal uso foi para a fabricação de lápis, que no município de Iguape chegou a envolver 250 famílias, direta ou indiretamente com a atividade (Diegues, 1991).

A atividade relacionada à extração de caixeta inicia seu declínio na década de 80 , pela entrada no mercado de madeira oriunda de plantações (Pinus sp.), pela super exploração dos caixetais da região e conseqüente inviabilização econômica da atividade (Diegues, 1991). A paralisação legal de seu corte foi em 1989, sendo que em 1992 a atividade foi regulamentada pela Resolução SMA 11/92 (Secretaria do Meio Ambiente do estado de São Paulo), devido às pressões do "movimento dos caixeteiros", pessoas que tradicionalmente trabalhavam na extração e beneficiamento da caixeta, ONG's e instituições de ensino (Marquesini et al., 2000).

A Resolução SMA 11/92 assume como 12 anos o ciclo de corte para a caixeta, porém o ciclo não foi estabelecido a partir de estudos de crescimento. Para a busca da sustentabilidade do manejo florestal a longo prazo, é fundamental conhecer o crescimento da floresta e sua produtividade (Amaro \& Tome, 1999; Vanclay 1994). Esta informação é fundamental para o planejamento operacional do manejo e para estudos de viabilidade técnica e econômica (FAO, 1998).

A determinação de ciclos de corte sustentáveis é crucial para evitar a degradação dos recursos madeireiros tropicais (Kammesheidt, L. et al. 2001). Como são poucas as informações sobre incremento volumétrico para florestas tropicais, é comum que o volume de madeira colhida seja superior ao incremento da floresta, fazendo com que a 
disponibilidade de madeira decresça drasticamente, podendo inviabilizar as atividades relacionadas ao manejo florestal (Rompaey, 2001).

Dentro do contexto do manejo sustentável a caixeta apresenta algumas características que favorecem seu manejo, como: i) alta capacidade de reprodução vegetativa através de brotação de raízes e cepas, dispensando o plantio após a colheita; ii) possui de pequeno a médio porte, causando menos impacto durante a colheita; iii) alta dominância da caixeta e baixa diversidade de outras espécies arbóreas; e iv) a madeira de caixeta possui alto valor de mercado (Viana et al., 1996).

$\mathrm{O}$ conhecimento sobre o crescimento e produção florestal é uma informação básica para alcançar a sustentabilidade do manejo florestal. Isto é possível para o manejo dos caixetais, já que é desde 1995 é feito o acompanhamento do crescimento de caixetais, após a colheita em duas áreas experimentais.

\subsubsection{Objetivos}

(i) Conhecer o crescimento de caixetais manejados;

(ii) Estimar o ciclo de colheita para caixetais;

(iii) Verificar se o ciclo de colheita de 12 anos proposto pela Resolução SMA 11/92, que regulamenta o manejo da caixeta, é aplicável.

\subsection{Materiais e Métodos}

\subsubsection{Clima}

O município de Iguape está localizado no litoral sul do Estado de São Paulo, próximo à foz do rio Ribeira de Iguape, imediatamente abaixo do Trópico de Capricórnio (IAC, 1990; Secretaria do Meio Ambiente, 1990). O clima da região segundo a classificação de Köeppen, é identificado como sendo do tipo Cfa, 
mesotérmico úmido, sem estações secas e déficit hídrico (Ramos Neto, 1993). A pluviosidade média anual é superior a $2.010 \mathrm{~mm}$ e a temperatura média anual superior a 20oC (Marquesini, 1994). Devido à influência de massas de ar Polar Atlântica no inverno, podem ocorrer geadas (Ramos Neto, 1993). Pelas características climáticas da região, observa-se que não existem condições que acarretem em sazonalidade no desenvolvimento vegetal, ou seja, o crescimento se mantém praticamente constante em todas as estações do ano.

\subsection{2 Área de estudo}

Os inventários florestais foram instalados em duas áreas distintas no município de Iguape, a primeira área é denominada Fazenda Retiro, localizada no bairro Retiro e a outra área é denominada Fazenda Cindumel, localizada no bairro Itimirim. A área do caixetal da Fazenda Retiro é de aproximada de 15 ha, ocorrendo em uma várzea pequena cercada por morros. Já o caixetal da Fazenda Cindumel apresenta área extensa de aproximadamente 45 ha, inserida numa grande planície alagável.

O caixetal da Fazenda Retiro é caracterizado, segundo a classificação proposta por Ziller (1992) e adaptada por Silva et al. (1999), como sendo de estágio sucessional médio. Este estágio sucessional é caracterizado por apresentar lençol freático aparente com lâmina d'água não permanente, formação florestal não pioneira, dossel superior a $10 \mathrm{~m}$. A caixeta é a espécie arbórea dominante, com densidade relativa superior a 70\% para os indivíduos acima de $5 \mathrm{~cm}$ de DAP; outras espécies ocorrem em baixa freqüência e densidade. Apresenta muitas epífitas, principalmente bromeliáceas (Silva et. al., 1999).

O caixetal da Fazenda Cindumel é caracterizado como sendo de estágio sucessional médio avançado. Este estágio sucessional é caracterizado por apresentar lençol freático aparente com a formação de lâmina d'água somente após grandes precipitações; dossel superior a $12 \mathrm{~m}$. e árvores emergentes podendo atingir $20 \mathrm{~m}$. A caixeta é a espécie dominante com densidade relativa entre 50 a 70\%; porém ocorrem espécies de áreas ciliares em maior densidade e frequiência; como o Euterpe edulis (palmito juçara), que se comporta como espécie comum (Silva et al., 1999). 


\subsubsection{Inventário florestal}

O inventário pré-colheita na Fazenda Retiro foi realizado entre janeiro e março de 1994. O sistema de amostragem utilizado foi o sistemático com início aleatório. As parcelas eram retangulares com largura fixa de $10 \mathrm{~m}$ e comprimento variável, este último determinado pela largura do caixetal. As parcelas eram subdivididas em subparcelas de $20 \mathrm{~m}$ de comprimento. Foram lançadas 12 parcelas o que correspondeu à uma área amostral de 2,26 hectares, intensidade amostral de 15,1\% da área total (Figura 6). A floresta foi explorada comercialmente pela primeira vez por volta de 1968 e em 1994 foi novamente colhida, situação muito comum na região (Silva, 2000).

O inventário pré-colheita da Fazenda Cindumel foi realizado entre março e julho de 1995, utilizando o mesmo sistema de amostragem e coleta de dados da área da Fazenda Retiro. A área do caixetal é de aproximadamente 45 ha, entretanto apenas 9,7 hectares foram considerados como área de pesquisa, em função da similaridade da composição e estrutura florestal e da topografia .Destes, a área amostrada foi de 1,38 ha (17,5\% da área) (Figura 7). Assim como na Fazenda Retiro, o caixetal se apresenta como um mosaico de ações antrópicas da exploração de madeira, sendo que partes da área já haviam sido colhidas em diferentes épocas (1985, 1994 e 1998) (Silva, 2000). 


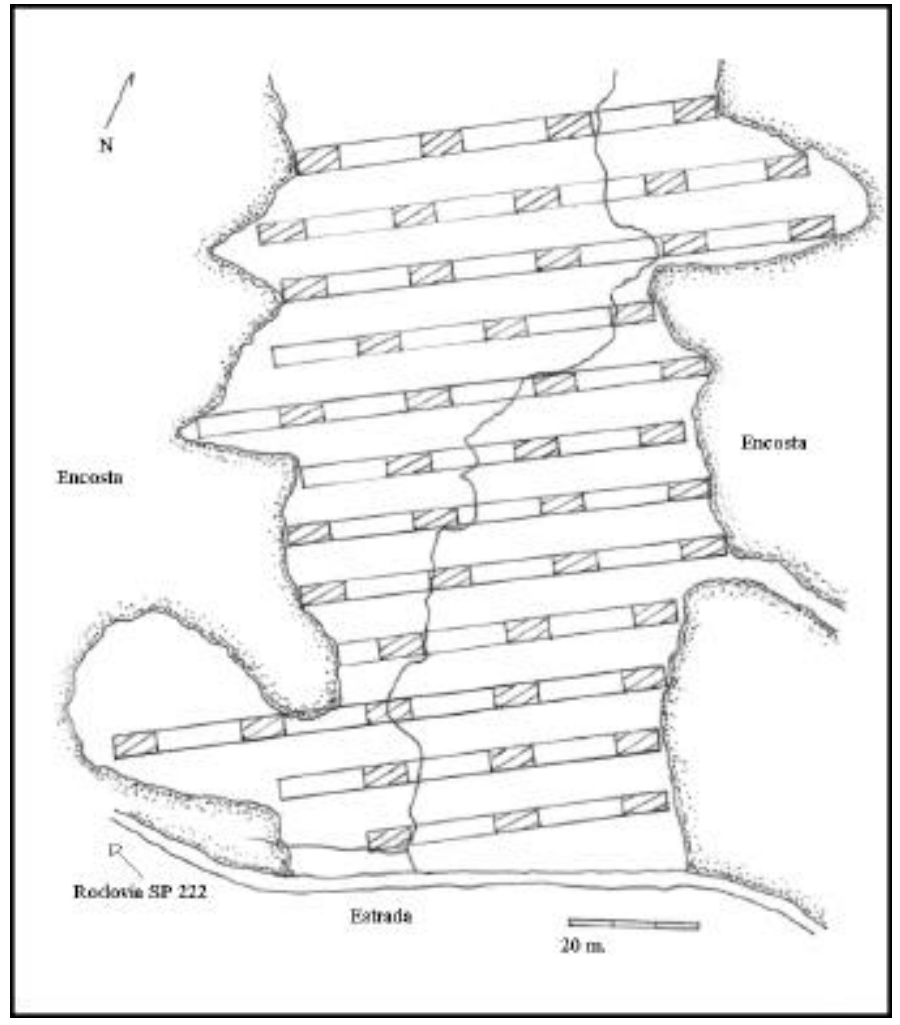

Figura 6 - Croqui do caixetal da área experimental da Fazenda Retiro, indicando as parcelas de inventário florestal (Silva, 2000)

O trabalho de campo visando a coleta dos dados do inventário florestal, consistiu inicialmente na localização das parcelas e das subparcelas e sua identificação no campo. Para identificação das parcelas foram localizados os canos que fazem a marcação do início das subparcelas e de árvores que se localizam à beira das mesmas. Feita a localização dos marcos de identificação, se procedeu à renovação da marcação, através de fita zebrada e pintura das árvores e canos. Após a localização e marcação das parcelas, se realizou a abertura das picadas limítrofes das parcelas. Posteriormente foi feita a coleta de dados de circunferência e número de brotos por cepa para todas as espécies arbóreas com CAP igual ou superior a $35 \mathrm{~cm}$ (11,2 cm DAP). 


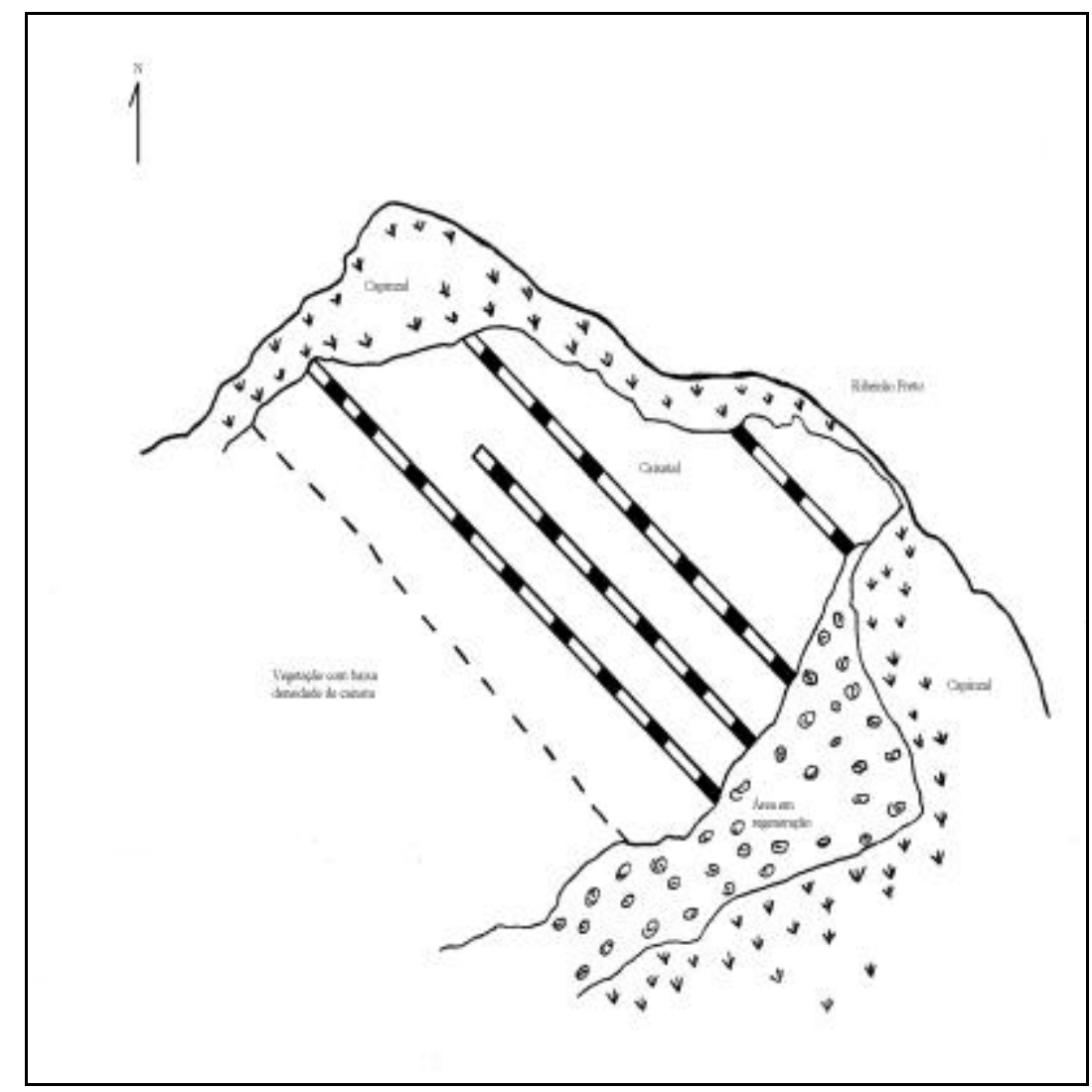

Figura 7 - Croqui, sem escala, da área experimental da Fazenda Cindumel, indicando as parcelas do inventário florestal (Silva, 2000)

\subsubsection{Incremento Volumétrico}

Durante o projeto "Ecologia e Manejo Integrado de caixeta - Tabebuia cassinoides (LAM.) DC. - no Vale do Ribeira/SP”, foram realizadas as primeiras medições do Inventário Florestal após a colheita. Esses dados foram utilizados para o cálculo do incremento volumétrico. Na Fazenda Retiro a primeira medição ocorreu 2 anos após a colheita da área. Na Fazenda Cindumel a primeira medição ocorreu 1 ano 
após a colheita. Desta forma, foram realizadas 4 medições na Fazenda Retiro e 3 na Fazenda Cindumel, conforme Tabela 10.

Tabela 11. Época das medições do Inventário Florestal nas áreas experimentais

\begin{tabular}{lll}
\hline Área Experimental & Colheita & Medição do Inventário Florestal \\
\hline Fazenda Retiro & 1994 & $1996,1998,2000$ e 2002 \\
Fazenda Cindumel & $1996-1997$ & 1998,2000 e 2002 \\
\hline
\end{tabular}

Para a determinação do incremento volumétrico, o primeiro passo foi a determinação do volume de madeira existente por parcela, para cada um dos anos de medição. Para o cálculo do volume comercial de foi utilizada a equação de volume local para caixeta, ajustada por Batista et al. (2002) (Equação 1). Esta equação assume como diâmetro mínimo de tora para aproveitamento o diâmetro de $7 \mathrm{~cm}$. A utilização de uma equação de volume local, que retorna o volume em função do DAP, se deve ao fato que na coleta de dados do Inventário Florestal não era feita a medição de altura, visando a redução de custos.

$$
\mathrm{V}=-12,6786+\mathrm{e}^{(-1,1670-0,1811}{ }_{\mathrm{KC}}^{\mathrm{I}} \mathrm{d}^{\left(2,1425-0,0369 \mathrm{I}_{\mathrm{KB}}\right)^{\prime}}
$$

onde:

$$
\begin{aligned}
& \mathrm{v}-\text { volume comercial }\left(\mathrm{dm}^{3}\right) \\
& \mathrm{d}-\mathrm{DAP}(\mathrm{cm}) \\
& \mathrm{I}_{\mathrm{KB}}-\text { variável indicadora da região } \mathrm{B} \text { (Litoral Norte) } \\
& \quad \mathrm{I}_{\mathrm{KB}}=1 \text { se a região for } \mathrm{B}, \mathrm{I}_{\mathrm{KB}}=0 \text { nos demais casos } \\
& \mathrm{I}_{\mathrm{KC}-\text { variável indicadora da região } \mathrm{C} \text { (Médio Vale do Ribeira) }} \\
& \quad \mathrm{I}_{\mathrm{KC}}=1 \text { se a região for } \mathrm{C}, \mathrm{I}_{\mathrm{KC}}=0 \text { nos demais casos }
\end{aligned}
$$

Como os dois caixetais experimentais localizam-se na região do Baixo Vale do Ribeira, as variáveis indicadoras de região assumem valor 0 (zero). 
A opção em se utilizar como diâmetro mínimo comercial o valor de $7 \mathrm{~cm}$, é em decorrência de um maior aproveitamento dos recursos madeireiros. A adoção de plano de manejo em conjunto com pesquisas de mercado e novos produtos, têm viabilizado a utilização de madeira de menor diâmetro, principalmente para a confecção de artesanato e demais produtos que aproveitem este tipo de madeira.

Após a determinação do volume individual, o mesmo foi totalizado por subparcela, para cada um dos anos de medição e transformado em volume por hectare. A partir daí, foi determinado o incremento volumétrico anual por parcela. Para o cálculo do incremento anual em volume é utilizada a fórmula definida por Finger (1992). (Equação 2). O mesmo método foi utilizado por Devoe \& Cole (1998) para o estudo do crescimento de manguezais manejados na Micronésia.

$$
\mathrm{IMA}=\left(\mathrm{V}_{\mathrm{F}}-\mathrm{V}_{\mathrm{I}}\right) / \mathrm{n}
$$

onde: IMA - incremento médio anual $\left(\mathrm{m}^{3} / \mathrm{ha} / \mathrm{ano}\right)$;

$\mathrm{V}_{\mathrm{I}}$ - volume no início do período $\left(\mathrm{m}^{3} / \mathrm{ha}\right)$;

$\mathrm{V}_{\mathrm{F}}$ - volume no final do período $\left(\mathrm{m}^{3} / \mathrm{ha}\right)$;

$\mathrm{n}$ - período de tempo decorrido entre medições (ano).

\subsubsection{Determinação do ciclo colheita}

A determinação do ciclo de colheita foi baseada em função do volume retirado da floresta, do volume remanescente e do Incremento Médio Anual, para cada uma das florestas estudadas. O presente trabalho trata a questão do ciclo de colheita, a partir do pressuposto do Rendimento Sustentado, ou seja, que o ciclo é o período de tempo necessário para que a floresta atinja o volume de madeira que possuía antes da colheita (Equação 3). 
Ciclo $=\left(\mathrm{V}_{\text {retirado }}\right) /(\mathrm{IMA})$

(Equação 3)

onde: Ciclo - período em anos;

$\mathrm{V}_{\text {retirado }}$ - volume de madeira retirado da floresta $\left(\mathrm{m}^{3} / \mathrm{ha}\right)$;

IMA - incremento médio anual $\left(\mathrm{m}^{3} / \mathrm{ha} / \mathrm{ano}\right)$

\subsection{Resultados e Discussão}

As análises estatísticas necessárias foram realizadas com o programa estatístico S-Plus 2000.

\subsubsection{Incremento Médio Anual}

O Incremento Médio Anual (IMA) foi determinado para cada subparcela, considerando todos os indivíduos com CAP > $35 \mathrm{~cm}$ (DAP 11,2 cm), e posteriormente determinado o incremento médio para cada área experimental. Não foi possível isolar o recrutamento e mortalidade de indivíduos de caixeta ou outras espécies, pois o acompanhamento era realizado a nível das subparcelas como um todo e não a nível de árvores individuais.

Para o caixetal da Fazenda Retiro observourse o valor de 3,215 m3/ha/ano para o Incremento Médio Anual (Tabela 11). Os dados utilizados para a obtenção da estimativa são provenientes de 50 subparcelas. Pelos valores de desvio padrão da média observa-se que o incremento médio anual não apresenta alta variabilidade, apesar da grande amplitude entre os valores mínimos e máximos observados. Isto pode ser devido à alta variação de micro hábitats dentro do caixetal, principalmente em função da densidade arbórea, da altura da lâmina d'água e intervenções antrópicas. 
Tabela 12. Incremento Médio Anual em volume, considerando indivíduos com CAP > $35 \mathrm{~cm}$, Fazenda Retiro, Iguape/SP

\begin{tabular}{|c|c|c|c|c|}
\hline Informações & $\begin{array}{c}\text { Período } \\
1996 \text { a } \\
1998\end{array}$ & $\begin{array}{c}\text { Período } \\
1998 \text { a } \\
2000\end{array}$ & $\begin{array}{c}\text { Período } \\
2000 \text { a } \\
2002\end{array}$ & $\begin{array}{c}\text { Média do } \\
\text { período } \\
\text { analisado }\end{array}$ \\
\hline Incremento Médio & 3,197 & 2,901 & 3,550 & $3,215 \pm 0,366$ \\
\hline \multicolumn{5}{|l|}{ Anual ( $\left.\mathrm{m}^{3} / \mathrm{ha} / \mathrm{ano}\right)$} \\
\hline Desvio padrão & 2,331 & 2,331 & 2,245 & 2,303 \\
\hline Mínimo (m³/ha/ano) & 0,096 & 0,417 & 0,541 & \\
\hline Máximo (m³/ha/ano) & 8,972 & 9,825 & 9,209 & \\
\hline Subparcelas $(10 \times 20$ & 55 & 50 & 50 & \\
\hline m) & & & & \\
\hline
\end{tabular}

* Intervalo de Confiança a 95\% de probabilidade

Para o caixetal da Fazenda Cindumel observa-se que o Incremento Médio Anual foi de $5,557 \mathrm{~m} 3 / \mathrm{ha} /$ ano para os indivíduos de caixeta com CAP $>35 \mathrm{~cm}$. Os dados utilizados para a obtenção das estimativas são provenientes de 46 subparcelas $(10$ x 20 m), distribuídas em 4 parcelas (Tabela 12). Assim como o caixetal da Fazenda Retiro, o caixetal da Fazenda Cindumel também não apresenta grande variabilidade entre os incrementos obtidos por subparcelas. 
Tabela 13. Incremento Médio Anual em Volume, considerando indivíduos com CAP > $35 \mathrm{~cm}$, para a Fazenda Cindumel, Iguape/SP

\begin{tabular}{lccc}
\hline \multicolumn{1}{c}{ Informações } & $\begin{array}{c}\text { Período 1998 a } \\
\mathbf{2 0 0 0}\end{array}$ & $\begin{array}{c}\text { Período 2000 a } \\
\mathbf{2 0 0 2}\end{array}$ & $\begin{array}{c}\text { Média do período } \\
\text { analisado }\end{array}$ \\
\hline Incremento Médio & 4,748 & 6,384 & $5,557 \pm 0,598$ \\
Anual (m ${ }^{3} /$ ha/ano) & & & \\
Desvio pa drão & 2,863 & 2,741 & \\
Mínimo $\left(\mathrm{m}^{3} / \mathrm{ha} / \mathrm{ano}\right)$ & 0,688 & 0,867 & \\
Máximo (m $\left.\mathrm{m}^{3} / \mathrm{ha} / \mathrm{ano}\right)$ & 12,725 & 12,907 & \\
Subparcelas $(10 \times 20$ & 46 & 46 & \\
$\mathrm{~m})$ & & & \\
\hline
\end{tabular}

* Intervalo de Confiança a 95\% de probabilidade

O caixetal da Fazenda Cindumel apresenta um maior incremento em volume que o caixetal da Fazenda Retiro, isso pode ser devido ao fato de que o caixetal da Fazenda Cindumel seja mais denso e tenha maiores indivíduos de caixeta.

Apesar do acompanhamento do crescimento dos caixetais estar sendo feito desde 1995 na Fazenda Retiro e desde 1998, na Fazenda Cindumel, o tempo de acompanhamento não é o ideal. O período ideal de acompanhamento que permitiria inferências mais seguras sobre o incremento dos caixetais deveria ser igual ao ciclo estimado de colheita, que é de 12 anos.

O IMA médio de 4,4 m3/ha/ano, determinado para os caixetais manejados em Iguape, é similar ao encontrado para manguezais manejados na Micronésia que segundo Devoe e Cole (1998) é de 4,5 m3/ha/ano. Já estudos de acompanhamento realizados durante 16 anos em floresta de Terra Firme no Pará indicam que o IMA é de 2,56 $\mathrm{m} 3 / \mathrm{ha} / \mathrm{ano}$ e $0,75 \mathrm{~m} 3 / \mathrm{ha} / \mathrm{ano}$, considerando-se todas as espécies e apenas as espécies com valor econômico, respectivamente (Alder \& Silva, 2000). Comparativamente às florestas de Terra Firme da Amazônia, as florestas de caixeta apresentam IMA significativamente superior.

As áreas experimentais só receberam como prática silvicultural a desbrota. Possivelmente a adoção de outras práticas silviculturais como desbaste, desrama e 
enriquecimento pode contribuir para o aumento do incremento volumétrico dos caixetais e melhoria da qualidade de fuste. Desta forma, é fundamental o desenvolvimento de pesquisas sobre a aplicação de outras práticas silviculturais, visando a sustentabilidade do manejo de caixetais.

\subsubsection{Intensidade de colheita}

Para a determinação do ciclo de colheita para as áreas experimentais foi determinada a intensidade de colheita em relação ao volume de madeira existente na área e o volume remanescente. A Tabela 13 apresenta o volume de madeira existente antes da colheita, volume de madeira remanescente e intensidade média de colheita (\%), para cada uma das áreas experimentais.

Tabela 14. Volume de madeira existente e remanescente $\left(\mathrm{m}^{3} / \mathrm{ha}\right)$ e intensidade de colheita para as áreas experimentais, Iguape/SP.

\begin{tabular}{lccc}
\hline Local & $\begin{array}{c}\text { Volume de madeira } \\
\text { existente }(\mathbf{m 3 / h a})\end{array}$ & $\begin{array}{c}\text { Volume de madeira } \\
\text { remanescente }(\mathbf{m 3} / \mathbf{h a})\end{array}$ & $\begin{array}{c}\text { Intensidade de } \\
\text { colheita }(\boldsymbol{\%})\end{array}$ \\
\hline Fazenda Retiro & 94,70 & 44,14 & 56,43 \\
Fazenda Cindumel & 118,25 & 38,57 & 62,73 \\
\hline
\end{tabular}

Observa-se que a intensidade mé dia de colheita foi superior a $50 \%$ do volume de madeira comercial de cada floresta. A maior intensidade de colheita para a Fazenda Cindumel se deve ao fato de que a madeira se destinava à produção de lápis, cujo diâmetro de tora mínimo para aproveitamento é igual a $7 \mathrm{~cm}$, enquanto que a madeira da Fazenda Retiro se destinava à produção de tamancos, cujo diâmetro mínimo para aproveitamento é igual a $12 \mathrm{~cm}$. Isto ocasionou a colheita de indivíduos com diâmetros menores. Aliado a isto, houve uma autorização especial por parte do DEPRN, reduzindo o diâmetro mínimo de colheita para $12 \mathrm{~cm}$, dessa forma, em função do produto a que se destinava a madeira e a redução do diâmetro mínimo de colheita houve maior intensidade de colheita. 
Como a intensidade média foi obtida através das intensidades de colheita de cada subparcela individualmente, observou-se que houve grande variabilidade nas intensidades de colheita ao longo das parcelas (Tabela 14). Esta grande variabilidade, de $0,15 \%$ a $94,5 \%$, é função principalmente da proximidade das áreas colhidas às rotas de extração, linhas de trole, valas ou corpos d'água. Como toda a colheita e extração de caixeta é feita manualmente, observou-se que a intensidade de colheita tem relação direta com a proximidade da linha de extração. Isto acaba gerando em alguns locais dentro da floresta situações muito parecidas a um corte raso, que pode trazer problemas de alteração na estrutura e composição da floresta e mesmo interferir no seu crescimento.

Tabela 15. Intensidades de colheita, mínima e máxima observadas para as áreas experimentais, Iguape/SP

\begin{tabular}{lcc}
\hline Local & $\begin{array}{c}\text { Intensidade } \\
\text { mínima }(\%)\end{array}$ & $\begin{array}{c}\text { Intensidade } \\
\text { máxima (\%) }\end{array}$ \\
\hline Fazenda Retiro & 0,15 & 92,33 \\
Fazenda Cindumel & 4,17 & 94,53 \\
\hline
\end{tabular}

Buscando verificar a intensidade da colheita sobre o crescimento da floresta, foram estabelecidas 3 classes de intensidade de colheita: (i) baixa $-<50 \%$; (ii) média - entre $51 \%$ e $75 \%$, e; (iii) alta - > 76\%. A partir daí foi determinado o IMA para cada classe de intensidade de colheita (Tabela 15). 
Tabela 16. Incremento Médio Anual $\left(\mathrm{m}^{3} / \mathrm{ha} / \mathrm{ano}\right)$ por classe de intensidade de colheita para as áreas experimentais, Iguape/SP

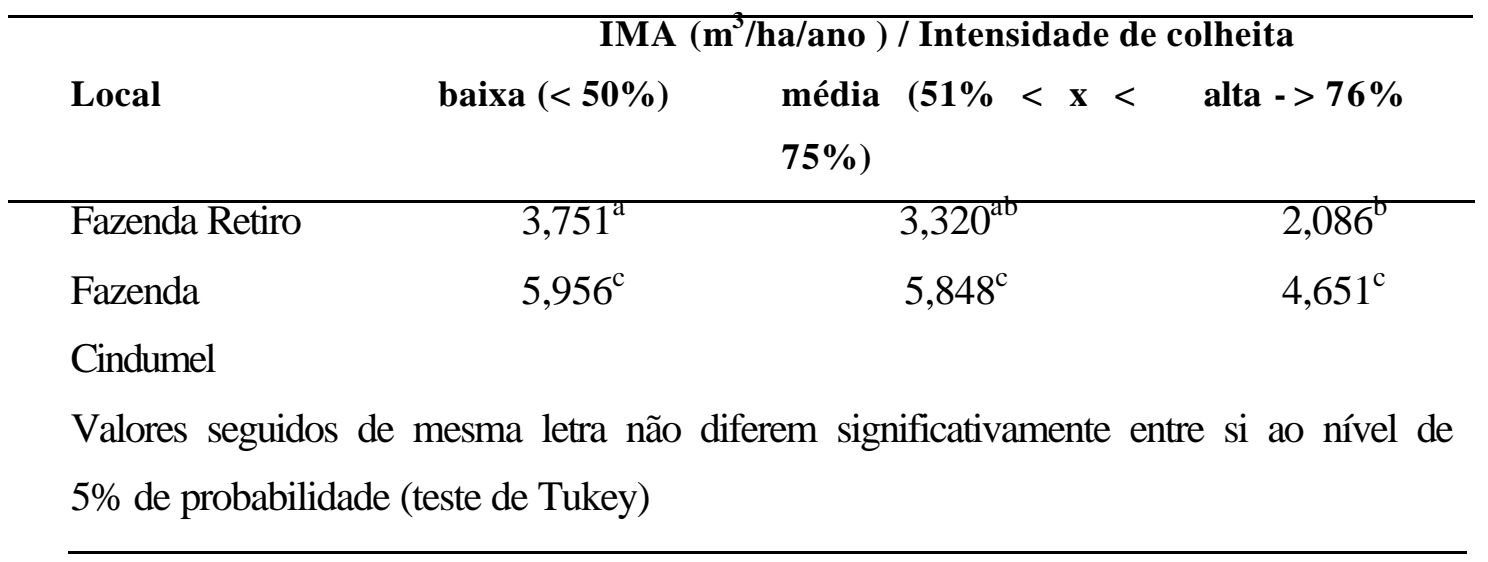

A partir dos valores de IMA por classe de intensidade de colheita, observou-se que há uma redução do IMA com o aumento da intensidade de colheita. Na Fazenda Retiro a redução do IMA foi bastante significativa entre as classes com baixa e alta intensidade de colheita, sendo que a redução ficou em torno de $1,7 \mathrm{~m}^{3} / \mathrm{ha} / \mathrm{ano}$, que corresponde a uma queda de 54\% no IMA.

Na Fazenda Cindumel também houve redução no IMA entre as áreas com baixa e média intensidade e o IMA da área com alta intensidade de colheita. A redução foi em torno de $1,2 \mathrm{~m}^{3} / \mathrm{ha} / \mathrm{ano}$. Comparativamente o caixetal da Fazenda Retiro parece ser mais sensível ao aumento na intensidade de colheita, pois se observam maiores reduções no IMA entre uma classe e outra de intensidade de colheita, do que o caixetal da Fazenda Cindumel.

Isto indica que deve haver um controle maior sobre a intensidade de colheita para que a mesma seja realizada dentro de níveis sustentáveis. A intensidade de colheita deveria ser distribuída o mais homogênea possível dentro da floresta, nunca ultrapassando o limite de $75 \%$ do volume passível de colheita da floresta. Como são poucas informações sobre o efeito da intensidade de colheita sobre a sustentabilidade do manejo são necessários estudos sobre seus efeitos sobre o crescimento, estrutura e composição da floresta manejada. 


\subsubsection{Ciclo de colheita}

Para a determinação do ciclo de colheita foram utilizadas as informações sobre o volume médio de madeira retirada na colheita e o IMA apresentado pelos caixetais estudados, com seus respectivos intervalos de confiança. O ciclo de colheita foi definido como sendo o tempo necessário para que a floresta atinja o mesmo volume que possuía antes da colheita. Como foi estabelecido um Intervalo de Confiança (95\% de probabilidade) para o IMA, o ciclo de colheita também é apresentado como intervalo de tempo (Tabela 16).

Tabela 17. Volume de madeira colhido, IMA e ciclo de colheita para as áreas experimentais, Iguape/SP.

\begin{tabular}{llll}
\hline Local & $\begin{array}{l}\text { Volume } \\
\text { colhido }\left(\mathbf{m}^{\mathbf{3}} / \mathbf{h a}\right)\end{array}$ & $\begin{array}{l}\text { Incremento médio } \\
\left(\mathbf{m}^{\mathbf{3}} / \mathbf{h a} / \mathbf{a n o}\right)\end{array}$ & $\begin{array}{l}\text { Ciclo estimado } \\
(\mathbf{a n o s})\end{array}$ \\
\hline Fazenda Retiro & 50,15 & $2,849<\mathbf{3 , 2 1 5}<3,581$ & $14,0<\mathbf{1 5 , 6}<17,6$ \\
Fazenda Cindumel & 79,68 & $4,959<\mathbf{5 , 5 5 7}<6,155$ & $12,9<\mathbf{1 4 , 3}<16,1$ \\
\hline
\end{tabular}

De acordo com os Ciclos de Colheita obtidos para as Fazendas Retiro e Cindumel (Tabela 16), observa-se que o ciclo proposto de 12 anos pela Resolução SMA 11/92, é inferior ao limite inferior estimado para o Intervalo de Confiança do Ciclo de Colheita para as duas áreas. Desta forma, assumi-lo como sendo válido é extremamente arriscado para a sustentabilidade do manejo, assim como, inviabiliza qualquer planejamento e análise de viabilidade econômica e ambiental da atividade.

Com isso deve ser feita uma revisão na Resolução SMA 11/92, alterando o Ciclo de Colheita para a caixeta de 12 anos para pelo menos 16 anos, que é o limite superior para a Fazenda Cindumel e maior que o ciclo médio da Fazenda Retiro. Apesar disto, estas informações sobre o ciclo de colheita devem ser consideradas com uma certa precaução, já que o período de acompanhamento dos caixetais ainda é inferior a metade do ciclo de 16 anos e pode ainda haver alterações no IMA dos caixetais. Este fato, evidencia a necessidade de se continuar com o acompanhamento 
do Inventário Florestal para que se possam ter bases mais sólidas para inferências sobre o ciclo de colheita e o manejo da espécie.

Comparativamente a outras formações florestais o ciclo de corte para caixetais é bastante reduzido, Silva et al. (1995) estimam o ciclo para floresta de Terra Firme como sendo de 30 - 35 anos. Já Kammescheidt et al. (2001) estudando manejo florestal na Venezuela estima que o ciclo de corte deva ser de 60 anos. Devoe \& Cole (1998), estudando manguezais na Micronésia para a produção de madeira para lenha, DAP igual a $10 \mathrm{~cm}$, observou que o ciclo de colheita variava de 9 a 52 anos.

\subsection{Conclusões}

O Incremento Médio Anual Médio para o caixetal da Fazenda Retiro foi de 3,215 \pm 0,366 $\mathrm{m}^{3} / \mathrm{ha} /$ ano (6 anos de acompanhamento) e para o caixetal da Fazenda Cindumel foi de 5,557 \pm 0,598 $\mathrm{m}^{3} /$ ha/ano (4 anos de acompanhamento). O maior incremento do caixetal da Fazenda Cindumel em relação ao da fazenda Retiro provavelmente se deve ao fato do primeiro apresentar maior densidade de caixeta e por apresentar formação florestal de maior porte.

As áreas de estudo apresentaram alta variação na intensidade de colheita dentro da floresta. A intensidade média de colheita foi de 56,43\% e 62,73\%, na Fazenda Retiro e Cindumel, respectivamente. A maior intensidade de colheita está relacionada com a proximidade das rotas de extração, chegando a atingir 94,53\% de retirada do volume de madeira passível de colheita e do tipo de produto a que se destina a madeira. As subparcelas que apresentaram intensidade de colheita superior a $76 \%$ do volume, sofreram redução significativa no IMA.

O intervalo do ciclo de colheita foi de 14 - 17,6 anos para o caixetal da Fazenda Retiro e de 12,6 - 16,1 anos para a Fazenda Cindumel. O ciclo estimado para o manejo de caixetais deve ser de pelo menos 16 anos, apesar disto, estas informações têm que ser interpretadas com precaução pois o tempo de acompanhamento dos caixetais é inferior àmetade do ciclo estimado. 
A partir dos resultados do estudo, se faz necessária uma revisão da legislação que regulamenta o manejo de caixeta no Estado de São Paulo, a Resolução SMA 11/92. A revisão deve atender os seguintes pontos principais: (i) estabelecer novo ciclo de colheita para o manejo de caixetais, e; (ii) estabelecer como limite máximo de intensidade de colheita $75 \%$ do volume passível de colheita.

Os resultados apontam também para a necessidade do acompanhamento do crescimento dos caixetais. Instalação de novos experimentos para acompanhar o recrutamento e mortalidade da caixeta e outras espécies, mudanças na estrutura e florística de caixetais manejados e a avaliação de outras práticas silviculturais como desbaste e desrama. 


\section{CONCLUSÃO GERAL}

O manejo da caixeta - Tabebuia cassinoides (LAM.) DC. - é regulamentado pela Resolução SMA 11 de 13 de abril de 1992 (Secretaria do Meio Ambiente do Estado de São Paulo). Esta resolução estabelece normas para a exploração de caixeta sob regime sustentado. As normas foram estabelecidas em função das informações técnicocientíficas da época, anterior ao início das pesquisas. Desta forma, é necessário que seja feita a incorporação dos avanços obtidos pelas pesquisas científicas.

Silva (2000) apresentou sugestões para a revisão da Resolução SMA 11/92, a partir de um processo participativo, sendo que os principais pontos previstos foram: (i) licenciamento de posseiros; (ii) diâmetro mínimo de corte; (iii) manutenção de árvores porta-sementes; (iv) época de desbrota; (v) talhonamento; (vi) aproveitamento de epífitas; (vii) manejo de cipós, e ; (viii) definição de caixetais. Até o momento as sugestões propostas não foram incorporadas à Resolução SMA 11/92. A partir dos resultados das pesquisas de acompanhamento das brotações e do inventário florestal após a colheita, pretende-se incluir novos pontos para a revisão da legislação, buscando seu aprimoramento e com isto estimular o manejo florestal da espécie e possibilitar a adoção do manejo como estratégia para a conservação para outras espécies.

A Resolução SMA 11/92, não faz nenhuma menção à intensidade de colheita para a caixeta, exige apenas que sejam mantidas 20 árvores porta-sementes por hectare. Pelas observações dos caixetais experimentais da Fazenda Retiro e Cindumel, localizados em Iguape, observou-se que a intensidade de colheita foi muito variável dentro do caixetal, variando de $0,15 \%$ a $94 \%$, o que representa uma área praticamente sem intervenção e outra praticamente à corte raso. A grande variação de intensidade é devida, principalmente a dois fatores: (i) proximidade das rotas de extração, e ; (ii) tipo de produto a que se destina a madeira. Como a colheita de caixeta é exclusivamente 
manual, nas áreas mais próximas às rotas de extração a intensidade de colheita é superior e diminui com o aumento da distância. $\mathrm{O}$ produto a que se destina a madeira também influencia significativamente na intensidade de colheita. No caso de madeira para lápis, que o diâmetro mínimo de aproveitamento é de $7 \mathrm{~cm}$, a colheita é mais intensa que para a produção de tamanco, onde o diâmetro mínimo de aproveitamento é de $12 \mathrm{~cm}$.

Observou-se uma redução significativa no IMA (Incremento Médio Anual) nas áreas que tiveram intensidade de colheita superior a 75\%, do volume passível de colheita. A redução do IMA foi em torno de $1,2 \mathrm{~m}^{3} / \mathrm{ha} / \mathrm{ano}$, o que representa uma perda de 54\%. Desta forma, é necessário o estabelecimento de um limite para a intensidade de colheita de até $75 \%$ do volume passível de colheita, para as áreas próximas às rotas de extração. Outro ponto é que a colheita seja feita de maneira mais homogênea na área, para evitar alterações na estrutura e composição florística, assim como aumento no ciclo de colheita.

A Resolução SMA 11/92, art. ⿹ㅗ, item IV, exige o compromisso do proprietário em realizar a desbrota de 12 a 18 meses após o corte e deixando até 3 brotos por touça. O acompanhamento do experimento de brotações de caixeta, 8 anos após a colheita, indica que devem ser deixados de 1 a 2 brotos por cepa. As cepas que possuem de 1 a 2 brotos por cepa apresentam desenvolvimento significativamente superior às cepas com 3 ou mais brotos.

Além do melhor desenvolvimento, há significativa melhoria da qualidade de fuste, como aumento da altura da 1ª bifurcação e menor tortuosidade. Isto é um fator relevante para o aumento do rendimento e aproveitamento de madeira nas colheitas futuras. Até o momento o número ideal de brotos a ser deixado por cepa é de 2, pois como apresenta a mesma performance quantitativa e qualitativa do tratamento com 1 broto, ao final do ciclo serão colhidos 2 fustes ao invés de 1, caso se mantenha a tendência observada.

O ciclo de colheita para caixeta, estabelecido pela Resolução SMA 11/92 é de 12 anos. Entretanto, o acompanhamento do inventário florestal das áreas experimentais indica que o ciclo de colheita para a caixeta deva ser superior ao estabelecido. 
O ciclo de colheita foi estabelecido como o tempo necessário para o caixetal manejado atingir o volume de madeira anterior à colheita. $\mathrm{O}$ Intervalo de Confiança para a estimativa do ciclo de colheita foi de 12,9 a 17,6 anos. Portanto, a proposta é que o ciclo a ser adotado seja de 16 anos. Como essa estimativa foi feita com base em 6 anos de acompanhamento do crescimento após a colheita, é necessária continuidade do acompanhamento do inventário florestal para refinamento das estimativas para o ciclo de colheita e se necessário posterior adequação. 
ANEXO 


\begin{abstract}
ANEXO A
RESOLUÇÃO SMA Nº 11, DE 13 DE ABRIL DE 1992

Estabelece normas para exploração da Caixeta (Tabebuia cassinoides) sob regime de rendimento auto-sustentado no Estado de São Paulo.

O Secretário do Meio Ambiente, considerando a necessidade de ser regulamentada a exploração sustentada da Caixeta (Tabebuia cassinoides) no Estado de São Paulo e com fundamento no que dispões o art. 14 da Lei ${ }^{\circ}$ 4.771/65 (Código Florestal), combinado com o art. $2^{\circ}$ da Instrução Normativa $n^{\circ}$ 84/91do Instituto Brasileiro de Meio Ambiente e dos Recursos Naturais Renováveis (Ibama), resolve:
\end{abstract}

Art. $1^{\circ}$. A Exploração da Caixeta (Tabebuia cassinoides) está condicionada à autorização do Departamento Estadual de Proteção de Recursos Naturais, de acordo com o Plano de Manejo Florestal elaborado nos termos desta resolução.

Art. $2^{\circ}$. Constitui-se instrumento indispensável à exploração da caixeta o Plano de Manejo Florestal, a ser apresentado pelo interessado no ato da solicitação da autorização, aonde deve constar:

I) O inventário florestal da espécie contendo:

a. frequiência de árvores porta - sementes, (nºhá);

b. distribuição diamétrica das árvores;

c. volume anual a ser explorado;

d. volume de outras madeiras a serem cortadas para construção da linha de vagonetes, bem como o local do corte.

II) Planta planialtimétrica da propriedade, contendo:

a. Delimitação das áreas de preservação permanente, de Reserva Florestal Obrigatória e da área a ser manejada;

b. Localização das valas e/ou linhas de escoamento da madeira; 
c. Talhões de exploração;

III) Cronograma da exploração e da condução da rebrota.

Parágrafo único . No caso de imóveis com área inferior a 50 hectares, é dispensável apresentação do Plano de Manejo Florestal, e, nesses casos, o levantamento de dados poderá ser feito pelo próprio interessado sob orientação, controle e fiscalização do órgão licenciador.

Art. $3^{\circ}$. São condições indispensáveis para a exploração da caixeta:

I. $\mathrm{O}$ corte somente de indivíduos com diâmetro à altura do peito (DAP) maior ou igual a 15 centímetros.

II. $\mathrm{O}$ corte de árvores de caixeta a uma altura de, no mínimo, 20 centímetros acima da linha d'água, no período de maior inundação do caixetal.

III. A manutenção de pelo menos 20 árvores de caixeta por hectare, adultas, sadias, e já em fase reprodutiva, a título de porta-sementes, distribuídas uniformemente pelo terreno.

IV. O compromisso do proprietário de providenciar a condução das rebrotas do caixetal, realizando-a entre 12 e 18 meses após o corte e mantendo até 3 brotos por touça.

V. A exploração anual de um volume máximo correspondente a 1/12 do total explorável, considerando-se o intervalo de corte de 12 anos para a espécie. Será aberta exceção às propriedades com caixetais muito pequenos, aonde seja inviável a extração por talhão.

Art. $4^{\circ}$. As valas ou linhas de transportes necessárias ao escoamento da madeira deverão ser locadas distando no mínimo 100 metros uma das outras, sendo permitida a locação de linhas convergindo a um mesmo acesso somente quando não houver outra alternativa de disposição, em condições a serem analisadas, pelas Equipes Técnicas do Departamento Estadual de Proteção dos Recursos Naturais. 
Art. $5^{\circ}$. O corte de outras espécies florestais existentes no caixetal só terá autorizado para o uso na construção da linha de vagonetes, sendo proibida sua comercialização.

Parágrafo único . É permitido o corte, ao nível da linha d'água, de quaisquer das espécies existentes no caixetal que estejam localizadas na linha de transporte da madeira.

Art. $6^{\circ}$. Todo transporte e armazenamento de caixeta depende de licença concedida pelo Departamento Estadual de Proteção de Recursos Naturais - DEPRN.

Art. $7^{\circ}$. O cumprimento desta Resolução será fiscalizado pelo Departamento Estadual de Proteção de Recursos Naturais - DEPRN e pela Polícia Florestal e de Mananciais.

Art. $8^{\circ}$. O não cumprimento das disposições estabelecidas nesta Resolução sujeita o infrator às penalidades previstas em lei.

Art. $9^{\circ}$. Esta Resolução entrará em vigor a partir da data de sua publicação, revogada a Portaria DEPRN - 10, de 1 de dezembro de 1989 e as demais disposições em contrário. 


\section{REFERÊNCIAS BIBLIOGRÁFICAS}

ALDER, D. SILVA, J. N. M. An empirical cohort model for management of Terra Firme forests in the Brazilian Amazon. Forest Ecology and Management, v. 130, $141-157$ p. 2000.

AMARO, A. TOME, M. (Org.) Empirical and process-based models for forest tree and stand growth simulation. Lisboa: Salamandra, 1999. 591 p.

BATISTA, J.LF., MARQUESINI, M., VIANA, V.M. Equações de volume para árvores de Caixeta (Tabebuia cassinoides) no estado de São Paulo e sul do estado do Rio de Janeiro. Scientia Forestalis, 2002 (no prelo).

CARVALHO, P. E. R. Espécies florestais brasileiras - Recomendações silviculturais, potencialidades e usos. EMBRAPA - CNPF. Brasília: EMBRAPA - SPI, 1994. 640p.

DEVOE, N. N. COLE, T. G. Growth and yield in mangrove forests of the Federated States of Micronesia. Forest Ecology and Management, v. 103, p.33 - 48, 1998.

DIEGUES, A. C. S. (coord.). A caixeta no Vale do Ribeira: estudo sócio-econômico da população vinculada à extração e desdobro da caixeta. São Paulo, NUPAUB-USP, 1991. 120p. 
FAO. Guidelines for the Management of Tropical Forests - The Production of wood. Roma: FAO, 1998. 293 p.

FINGER, C. A. G. Fundamentos de Biometria Florestal. Santa Maria/RS: USM/CEPEF/FATEC, 1992. 269 p.

FUNDAÇÃO SOS MATA ATLÂNTICA; INPE. Atlas dos Remanescentes Florestais da Mata Atlântica no Período 1995 - 2000 - Relatório Parcial Estado do Rio de Janeiro. $2001 \quad$ http://www.sosmatatlantica.org.br/atlas2001/atlas2001_rj.htm. (03jun.2001)

FUNDAÇÃO SOS MATA ATLÂNTICA; INPE b. Atlas da Evolução dos Remanescentes Florestais e Ecossistemas Associados no Domínio da Mata Atlântica no Período 1990 - 1995. 1998 http:|lwww.sosmatatlantica.org.br /index02.html. (03jun.2001)

HAMILTON, C. L. Managing coppice in Eucalypt plantations. Agriculture Notes, State of Victory, Department of Natural Resources and Environment, 2002.

4p. $\quad$ http://iufro.boku.ac.at/iufro/iufronet/d1/wu10700/unpub/confeval.htm\#a22. (31May.2001).

INSTITUTO AGRONÔMICO DE CAMPINAS - IAC. Macrozoneamento das terras da região do rio Ribeira de Iguape, SP. Campinas, 171 p. (Boletim Técnico, 19).

KAMMESHEIDT, L.; KÖHLER, P; HUTH, A. Sustainable timber harvesting in Venezuela: a modeling approach. British Ecological Society, Journal of Applied Ecology, v. 38, p.756 - 770 p. 2001. 
KÜNZEL, L. A.; BORSSATTO, I.; CAPITANI, L. R.; MAIA, S. M.; \& THOMAZ, S. K. Viabilidade econômica e considerações operacionais da reforma de eucalipto na Cenibra Florestal S.A. In: SEMINAR ON TECHNICAL AND ECONOMIC ASPECTS OF THE REFORM OF EUCALYPTUS PLANTATIONS. Belo Horizonte, 1987. SIF. 20 p.

LORENZI, H. Árvores brasileiras: Manual de identificação e cultivo de plantas arbóreas nativas do Brasil. Nova Odessa - SP: Editora Plantarum, 1992. 352p.

.MARQUESINI, M. Manejo de populações naturais de caixeta - Tabebuia cassinoides (LAM.) DC. - Fase I, levantamento de caixetais. Piracicaba: NUPAUB/USP Fundação Ford, 1994. 48 p. (Relatório de Pesquisa).

MARQUESINI, M.; VIANA, V.M.; BATISTA, J.L.F.; BERNHARDT, R.; NOLASCO, A.M.; PAULO, R.A. Manual Técnico sobre Ecologia e Manejo de Caixetais. 2000. 68 p. ( no prelo).

MATTHEWS, J. S. Silvicultural systems. Oxford: Oxford University , 1996. 304p.

MITTERMEIER, R.A. O País da Megadiversidade. Ciência Hoje, v. 14,n.81, p.20-27, maio/junho de 1992.

NOLASCO, A. M. Minimização e aproveitamento de resíduos florestais da Mata Atlântica: o caso da caixeta - Tabebuia cassinoides (LAM.) DC. São Carlos, 2000. 171 p. Tese (Doutorado) - Escola de Engenharia de São Carlos, Universidade de São Paulo.

RAMOS NETO, M.B. Análise Florística e Estrutural de duas florestas sobre a Restinga, Iguape, São Paulo. São Paulo, 1993. 129 p. Dissertação (Mestrado) - Instituto de Biociências, Universidade de São Paulo. 
RAUSCHER, H.M. Sprout/Coppice reponse. Encyclopedia of Southern Appalachian Forest Ecosystems.

http://www.forestryencyclopedia.net/?targetID=88\&anchorID=27. 20Jun.2003.

REIS, G.G. DO; REIS, M. DAS G. F. Fisiologia da brotação de eucalipto com ênfase nas suas relações hídricas. Série Técnica IPEF, V. 11, n.23, p. 9-22, maio. 1997.

ROAMPAEY, R.S.A.R. van. Contribution of big trees to total forest production: a case in Taï National Park, Côte d'ï voire. http://iufro.boku.ac.at/iufro/iufronet/d1/wu10700/unpub/confeval.htm\#a22. (31May.2001).

SECRETARIA DO MEIO AMBIENTE. Macrozoneamento do complexo estuarinolagunar de Iguape-Cananéia: Plano de gerenciamento costeiro. São Paulo,SMA, 41 p. (Série documento)

SILVA, J.N.M.; CARVALHO, J.O.P. de; LOPES, J. do C.A.; ALMEIDA, B.F. de; COSTA, D.H.M.; de OLIVEIRA, L.C.; VANCLAY, J.K.; SKOVSGAARD, J.P. Growth and yield of tropical rain forest in the Brazilian Amazonian 13 years after logging. Forest Ecology and Management, v. 71, p. 267 - 274, 1995.

SILVA, M.M.P. da. Subsídios para o manejo de Tabebuia cassinoides (Lam.) DC (caixeta) - ecologia, silvicultura e manejo florestal. Piracicaba, 2000. 105 p. Dissertação (Mestrado) - Escola Superior de Agricultura "Luiz de Queiroz", Universidade de São Paulo.

SILVA, M.M.P.; BERNHARDT, R.; VIANA, V.M. PAULO, R.A. Potencial de produção e prioridades para a conservação de caixetais no sudeste brasileiro. Piracicaba, Scientia Forestalis, 1999. (no prelo). 
VANCLAY, J.K. Modeling Forest Growth and Yield - Applications to Mixed Tropical Forests. Oxon: CAB International,1994. 12 p. 1994.

VIANA, V. M., AZEVEDO, T., MARQUESINI, M. Perspectivas para a certificação sócio-ambiental (selo verde) e manejo da caixeta (Tabebuia cassinoides). Florestar Estatístico, v.9,p.3-9, 1996.

ZILLER, S.R. Análise fitossociológica de caixetais. Curitiba, 1992. 101p. Dissertação (Mestrado) - Escola de Florestas, Universidade Federal do Paraná. 